\title{
Discovering the stacking landscape of a pyridine-pyridine system
}

\author{
Tomasz Sierański ${ }^{1}$ (D)
}

Received: 7 June 2017 / Accepted: 9 October 2017 /Published online: 9 November 2017

(C) The Author(s) 2017. This article is an open access publication

\begin{abstract}
Extremely extensive calculations of potential energy surfaces for the parallel-displaced configuration of pyridine dimer systems have been carried out using a dispersioncorrected density functional. Instead of focusing on stationary geometries these calculations provide much deeper insight into the "landscape" of the interaction energies of the particular systems - one can learn how the pyridine dimer stability changes along with various geometrical parameters. Other calculations such as natural bond orbital and energy decomposition have also been applied. The interplay of two significant factors, electrostatic forces and electron correlation effects, have been evaluated. The role of $\pi \cdots \pi$ interactions in the stacked pyridine systems has also been confirmed, and surprisingly, this happened to be true even for the geometries where the formation of $\mathrm{C}-\mathrm{H} \cdots \pi$ interactions might be proposed instead. The combination of many different methods has revealed the complexity of the stacking interactions. Apart from providing a "literal new look" into pyridine interaction patterns another picture has emerged. A stacking interaction in a pyridine dimer system is perceived as a combination of many different sources of the interaction energy, including orbital ones, and this is true for many different geometries.
\end{abstract}

Electronic supplementary material The online version of this article (https://doi.org/10.1007/s00894-017-3496-4) contains supplementary material, which is available to authorized users.

Tomasz Sierański tomasz.sieranski@p.lodz.pl

1 Institute of General and Ecological Chemistry, Lodz University of Technology, Zeromskiego 116, 90-924 Lodz, Poland
Keywords Stacking interactions $\cdot$ Pyridine .

Density-functional theory · Energy decomposition analysis . Natural bond orbital analysis

\section{Introduction}

Noncovalent interactions (NCI hereafter) in aromatic ring systems are significant in many areas of science. They play a key role in the structures of biomolecules, molecular recognition, material science, and nanoengineering [1-8]. This is especially true for the N-heterocyclic ring system. The presence of a nitrogen atom in their structures enriches their ring framework $\pi$-cloud with electrons and enables their participation in different interaction patterns (e.g., $\mathrm{C}-\mathrm{H} \cdots \mathrm{N}$ hydrogen bonds) [9-13]. Thus, N-heterocycles may be considered as useful recognition elements in many biological systems. They are also used as building blocks for anchoring substituents in defined position and become a key component in most known drug molecules $[9,14-16]$. Though the study of stacking interactions has mostly been focused on a benzene molecule and its simple derivatives [17-23], the number of studies of such interactions in the case of heterocyclic ring systems have been quickly increasing [9, 11, 24-29].

The most studied systems containing N-heterocycles are dimers containing pyridine molecules $[10,26,27$, 30-37]. The studies, in general, are focused on determination of system energy as a function of selected geometrical parameters but other approaches such as full geometry optimizations, starting from various unsymmetrical initial dimer arrangements, have also been applied [38]. In addition, quantum chemistry calculations have recently been combined with the statistical analysis based on data from the Cambridge Structural Database (CSD) [10, 26, 39-42]. This combination study appeared to be very 
useful and helped to learn a lot of the stacking interaction involving pyridine dimer systems (e.g., the existence of binding interaction for ring centroid distances larger than $6 \AA)[10,40]$. Though some significant progress has definitely been made, most studies only focus on analyzing stationary geometries and say nothing of a whole range of other configurations. The role of the molecular geometrical dependencies on the intermolecular interaction of the stacked systems is not fully understood and the exact binding geometrical boundaries (the boundaries between positive and negative interaction energies) of the stacked pyridine systems are not known since the accurate potential energy maps of these systems, based on several geometrical parameters, are not available. Some attempts have been made before, but the obtained PES map for a pyridine dimer was restricted only to two geometrical parameters with a relatively large distance step (the distance between pyridine monomers was changed with $1 \AA$ increments) [10]. Accurate PES maps would be very useful in providing information about the key importance of the complete understanding of the stacking interaction phenomenon, literally giving a new way to look into the stacked interactions patterns of pyridine systems. Instead of analyzing simple potential energy curves one could see a wider picture of what really occurs and learn how the pyridine dimer stability changes along with various geometrical parameters. A whole area of pyridine dimers possessing similar energy could be observed and one could know how one interaction, as different geometrical parameters change, transforms into another. Going beyond the analysis of the stationary geometries, multidimensional, accurate potential energy maps could find a very broad range of applications in chemistry. They would appear to be a guide for qualitative predictions of binding interactions and could help to learn more of the influence of the position of nitrogen atoms and $\mathrm{C}-\mathrm{H}$ bonds (e.g., the rotation of one monomer around the other) on the dimer system energy as well as determine the geometrical regions in which the interaction energy stays the same or changes negligibly, helping to harness the full potential of NCI (e.g., in predicting and understating the molecular packing patterns as well as in drug design strategy). This is true not only for pyridine based systems as the obtained knowledge may be transferred to other N-heterocycles. Moreover, when those multidimensional data are analyzed with the results of other methods, such as energy decomposition analysis methods and/or natural bond orbital analysis, they may disclose important aspects associated with the physics of NCI (e.g., the actual importance of $\pi$ orbitals in intermolecular interactions in stacked systems).

Taking all the above into account, as the main focus of this study, the extremely extensive analysis of potential energy surfaces (PES) of model pyridine-pyridine dimers has been selected. The interaction energies of approximately 25,000 systems have been calculated. Because of the use of a pyridine ring as a versatile core in the pharmaceutical field [43], the presented study may also be relevant in electronic properties of pyridine-unit-based drugs.

The accurate calculations of NCI interaction energies require an appropriate description of the dispersion forces. Hence, the use of advanced wave function theory (WFT) methods is needed. Unfortunately, they are very expensive and cannot be applied for routine calculations [44]. An alternative to those WFT methods are density functional theory (DFT) methods whose cost is significantly lower. Recently, a number of new density functionals enabling the energy calculations of non-covalently bonded systems have been developed. One of the simplest ways of accounting for dispersion forces is to add a dispersion correction term. This method is robust, very fast, and it is easily programmable. Some of dispersion-corrected density functionals, with D3-correction $[45,46]$, give results that in many cases are close to the advanced WFT methods for dispersion-dominated NCI [45-47]. Apart from adding a dispersion correction term, it is also worth mentioning the hybrid meta exchange-correlation functionals developed by the Truhlar Group, among which one of the most popular is M06-2X as it performs well in the general chemistry of main group elements and enables a great improvement in calculations of $\mathrm{NCI}$ interaction energies [48, 49].

\section{Methods}

In order to identify an appropriate density functional for the PES study, the selected density functionals, based on the literature data $[9,48-51]$ were tested against the S66x8 data set [52] for both stacked and hydrogen bonded pyridine dimer systems (Fig. 1). All the necessary geometries were taken from the Benchmark Energy and Geometry Data Base [53]. In the selected functionals both aug-cc-pVDZ and cc-pVDZ (respectively aDZ and DZ hereafter) basis sets were used. Since the energies of a high number of systems were to be calculated, taking into account higher basis sets would make the calculations extremely costly and time-consuming. B97D3, B3LYP-D3BJ, and M06-2X were selected as the tested DFT functionals. B97-D3 and B3LYP-D3BJ are a dispersioncorrected DFT with D3 version of Grimme's dispersion with Becke-Johnson damping [46]. They have been shown to describe NCI in many systems with aromatic rings [9, 46, 51]. M06-2X was selected due to its popularity and its good performance in calculation of NCI between aromatic molecules $[48,49]$. Among these functionals, B3LYP-D3BJ appeared to be the best. It gave excellent results for both hydrogen bonded and stacked pyridine dimers (Fig. 1). For this functional, the influence of diffuse functions ( $\mathrm{aDZ}$ vs $\mathrm{DZ}$ ) on the pyridine 


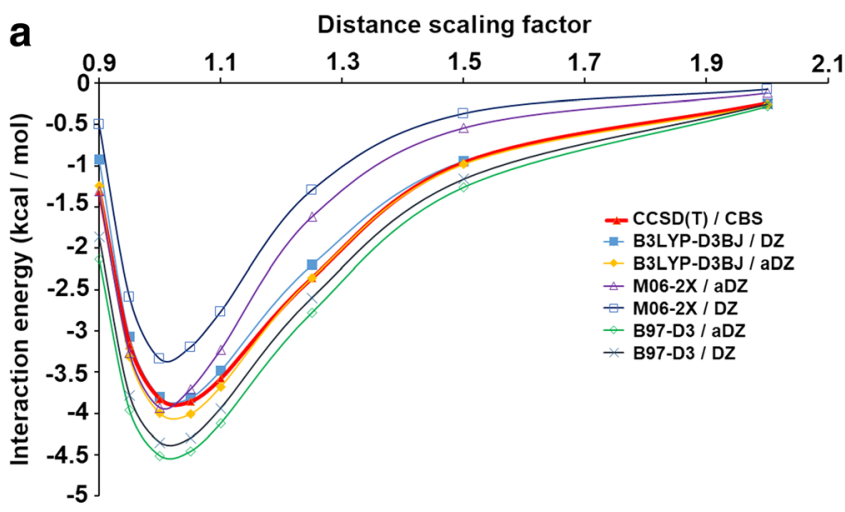

Fig. 1 Interaction energy curves created on the basis of data from Sx66 data set $[52,53]$ for both stacked (a) and hydrogen bonded (b) pyridine dimer systems. Distance scaling factors are the factors used for scaling the

system energy was negligible with the mean deviations from the reference $\operatorname{CCSD}(\mathrm{T})$ (coupled cluster with single, double, and perturbative triple excitation contributions) [44] equal to 0.12 and $0.16 \mathrm{kcal} \mathrm{mol}^{-1}$, respectively for $\mathrm{aDZ}$ and $\mathrm{DZ}$ (Fig. 1). The remaining functionals performed worse with the mean deviations values equal to $0.40,0.65,0.43$, and $0.38 \mathrm{kcal} \mathrm{mol}^{-}$ ${ }^{1}$, respectively for M06-2X/aDZ, M06-2X/DZ, B97-D3/aDZ, and B97-D3/DZ. It is also seen that in the case of M06-2X, the lack of diffuse functions significantly worsens the NCI energy calculations (Fig. 1). Taking this into account, the general performance and the calculation time, for all further calculations B3LYP-D3BJ with DZ was selected (the use of DZ instead of aDZ basis set significantly speeds up the computation) .

Model pyridine-pyridine systems were constructed as shown in Fig. 2. In each of them the pyridine rings were parallel to each other. PES scans were done as a function of four geometrical parameters: the aromatic ring center distance $(d)$, the twist angle $(\alpha)$ between the pyridine rings, the angle between the line connecting the aromatic ring centers and the normal line to the aromatic ring in which the connecting center line starts $(\beta)$ and the angle determining the rotation of one pyridine monomer around the other $(\gamma)$. All calculations were performed using Gaussian09 rev. D.01 [54]. The starting monomer was a pyridine molecule with geometry optimized at MP2/aDZ level, where MP2 stands for second-order Møller-Plesset perturbation theory [55]. The dimer energies were corrected for basis set superposition error by the use of the counterpoise method [56]. Interaction energies were calculated by subtracting the energy of the two monomers:

$\mathrm{E}_{\text {Interaction }}=\mathrm{E}_{\text {Dimer }}-\mathrm{E}_{\text {MonomerA }}-\mathrm{E}_{\text {MonomerB }}$

The pyridine-pyridine system energies were calculated as a function of the selected geometrical parameters. The parameter $d$ was varied from 3 to $7 \AA$ with $0.1 \AA$ increments, $\alpha$ was

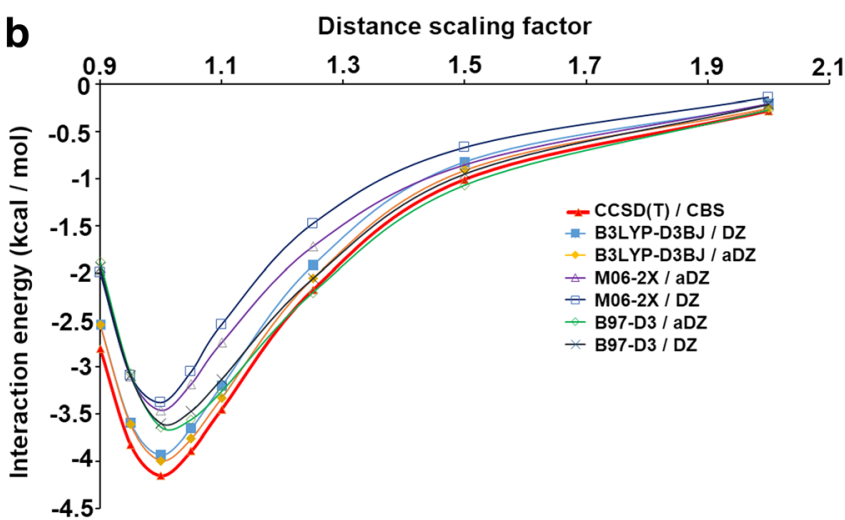

closest intermolecular distance starting from the equilibrium geometries $[52,53]$. The curves were created using splicing interpolation. CBS stands for complete basis set extrapolation

varied from 0 to $330^{\circ}$ with $30^{\circ}$ increments, $\beta$ was varied from 0 to $90^{\circ}$ with $10^{\circ}$ increments and $\gamma$ was varied from 0 to $180^{\circ}$ with $45^{\circ}$ increments. Because of the dimer system symmetry, taking into account higher $\gamma$ values was not necessary. For $\gamma=0^{\circ}$ the lateral shifting (associated with the increase in $d$ values at the given $\beta$ ) of one ring along the plane of the other was in accordance with the direction of the vector created between the other ring centroid and the nitrogen atom of this ring (the vector beginning was the position of the ring centroid).

On the basis of the obtained data (single points calculations for each system) the contour plots representing energy as a function of $\alpha$ and $\beta$ and as a function of $d$ and $\beta$ (Figs. 3 and 4) were created using OriginPro 2016 [57]. The model pyridine dimers, whose geometries correspond to the found global and local energy minima on the created PES maps, were optimized (at B3LYP-D3BJ/DZ) to get more accurate system configurations. For $\beta=90^{\circ}$ pyridine molecules, being coplanar, can create two $\mathrm{C}-\mathrm{H} \cdots \mathrm{N}$ hydrogen bonds. For this configuration, the interaction energy between pyridine molecules also appeared to strongly depends on $\gamma$ angle and a relatively large difference in energy between the non-optimized and optimized geometry was observed. Hence, an additional PES scan was made with $\beta$ and $d$ taken from the non-optimized geometry; $\alpha$ was varied from 0 to $330^{\circ}$ with $30^{\circ}$ increments and $\gamma$ was varied from 0 to $180^{\circ}$ with $10^{\circ}$ (Fig. 5).

Some intermolecular interactions in the investigated pyridine-pyridine systems (dimers whose geometries correspond to the found global and local energy minima as well as those with geometries corresponding to PES map regions in which the interaction energy stays the same or changes negligibly) were analyzed by means of localized molecular orbital energy decomposition analysis (LMO-EDA) [58]. LMOEDA can be considered as an extension and modification of the methods developed by Kitaura and Morokuma, Ziegler and Rauk, and Hayes and Stone [59-61]. This relatively 


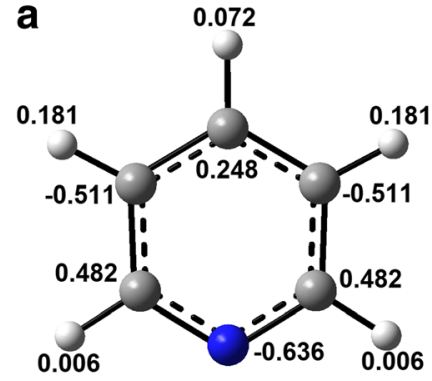

$\mu=2.2870 \mathrm{D}$ b

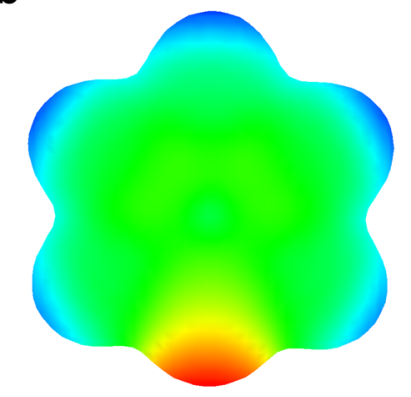

C

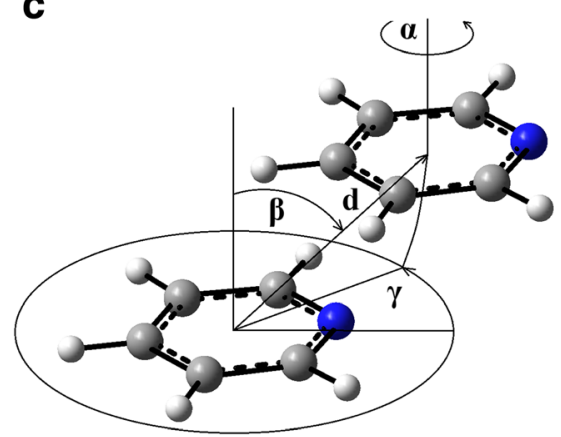

-0.08 au

0.07 au

Fig. 2 Atom HLY charge values (a), EPS map (b) calculated for a pyridine molecule and the geometrical model of a pyridine dimer (c) used in presented calculations ( $d$, the aromatic ring center distance; $\alpha$, the twist angle between the monomers; $\beta$, the angle between the line connecting the aromatic ring centers and the normal line to the aromatic ring in which the connecting center line starts). For all parameters equal to zero, the atom positions of one monomer are the same as the corresponding atom positions of the second one. HLY charge values (a) are given in $e$ (elementary electric charge), the EPS map (b) is superimposed on the isodensity surface with $0.005 \mathrm{au}$ new and robust method can be used with many quantum mechanical approaches (e.g., DFT and CC). Since its implementation in GAMESS software package [62, 63], LMO-EDA has been successfully used to study the intermolecular interactions (e.g., hydrogen bonds, $\pi \cdots \pi$, and $\mathrm{C}-\mathrm{H} \cdots \pi$ contacts) in a number of systems such as pyrrole-pyrrole dimers [9], indole-cation-anion complexes [64], aromatic units of amino acids with guanidinium cation [65], hydrogen-bonded complexes of serotonin [66], radical conjugated systems [67], and C-H/ $\pi$ complexes in water [68]. The interaction energy in LMOEDA is decomposed to electrostatic $\left(\mathrm{E}^{\mathrm{ele}}\right)$, exchange $\left(\mathrm{E}^{\mathrm{ex}}\right)$, repulsion $\left(\mathrm{E}^{\mathrm{rep}}\right)$, and polarization $\left(\mathrm{E}^{\mathrm{pol}}\right)$ terms and they are calculated on the basis of single-determinant Hartree-Fock (HF) wavefunctions. The correlation term $\left(\mathrm{E}^{\mathrm{corr}}\right)$, roughly dispersion, is derived from a supermolecule approach by the use of a correlation method (such as MP2 or CC) and it equals the difference between the correlation method energy and HF energy [58]. In this work, the contribution of correlation energy was estimated from B3LYP-D3BJ/DZ calculations and the $\mathrm{E}^{\mathrm{corr}}$ was calculated as a difference between B3LYPD3BJ/DZ energy and HF/DZ energy. The LMO-EDA calculations were made using GAMESS [62, 63] software employing the HF/DZ method. In the LMO-EDA calculation, as implemented in GAMESS, the counterpoise correction for basis set superposition error is used.

In order to find possible orbital interactions between the pyridine monomers, the electronic properties of the model pyridine dimers, whose geometries correspond to the found global and local energy minima as well as those with geometries corresponding to PES map regions in which the interaction energy stays the same or changes negligibly, were analyzed in terms of natural bond orbital (NBO) analysis with the use of hybrid meta exchange-correlation functional, M06-2X, employing aug-cc-pVTZ basis set. Those pyridine dimer geometries were also analyzed (at M06-2X/aug-cc-pVTZ level of theory) in terms of the $\mathrm{Hu}, \mathrm{Lu}$, and Yang (HLY) chargefitting method [69]. This method appeared to give better results than the commonly accepted CHelpG scheme [69, 70]. M06-2X density functional was selected due to its excellent performance during application in the general chemistry of main-group elements [48, 49].

\section{Results and discussion}

The performed calculations have enabled creation high quality PES maps that enable one to see how the pyridine dimer stability changes along with various geometrical parameters. On the basis of these maps the optimal configurations of the pyridine dimer may also be identified (Fig. 3). It is also observed that the binding boundaries on the PES maps are relatively broad and they are seen for different geometrical parameters.

The minimum $d$ set as $3 \AA$ is too small to provide binding interaction energies (negative ones) in pyridine dimers. Generally, with the increase in $d$ the interaction energy between the pyridine monomers decreases which encourages the pyridine molecules to bind to each other (Figs. 3 and 4). However, an optimal system configuration cannot be achieved by the monomers separation alone and other geometrical parameters need to be changed as well. Hence, a sandwich configuration is usually not associated with any energy minimum since it involves too much negative electrostatic repulsion. An exception is a small local energy minimum found for a pyridine configuration with $\gamma=0^{\circ}$ (Table 1). Constructing an optimal pyridine dimer configuration, charge separation in a molecule of pyridine needs to be taken into account as well. This charge separation is relatively high and complex. The HLY charge-fitting analysis shows that in a pyridine molecule the nitrogen atom and some carbon atoms are negatively 
$\gamma$ angle $\left({ }^{\circ}\right)$

0

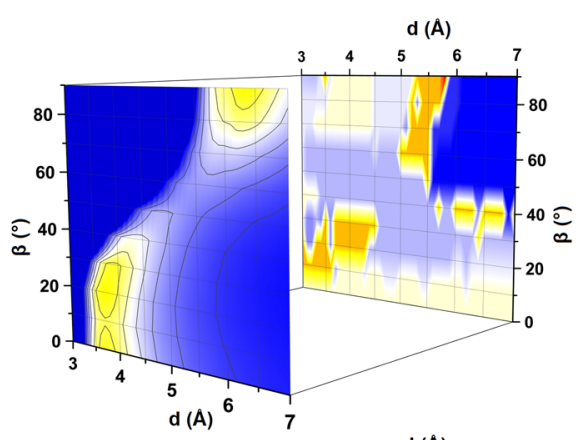

45

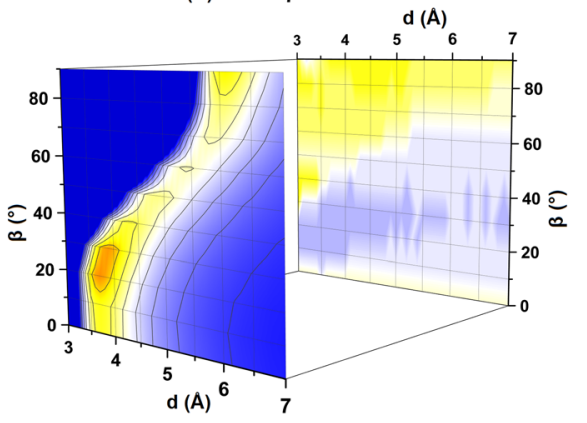

90

135
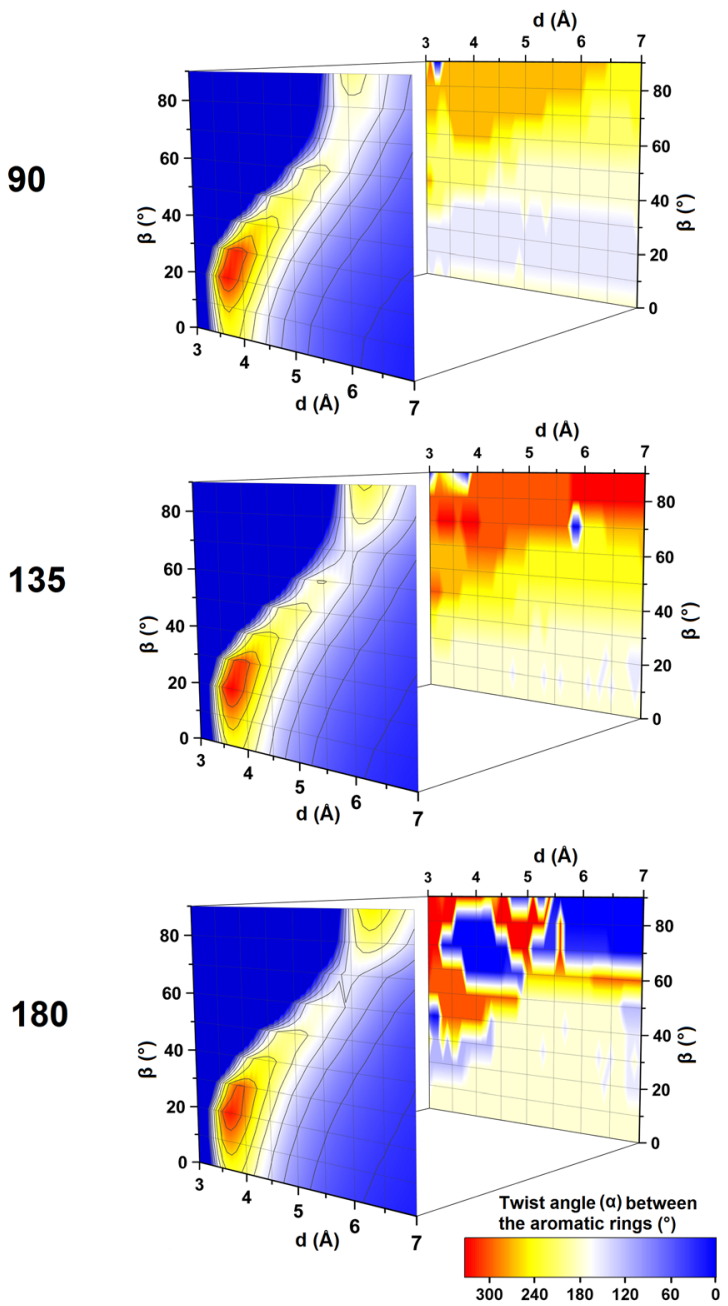

Interaction energy (kcal/mol)

$-3.60-3.00-2.40-1.80-1.20-0.60 \geq 0.00$
2

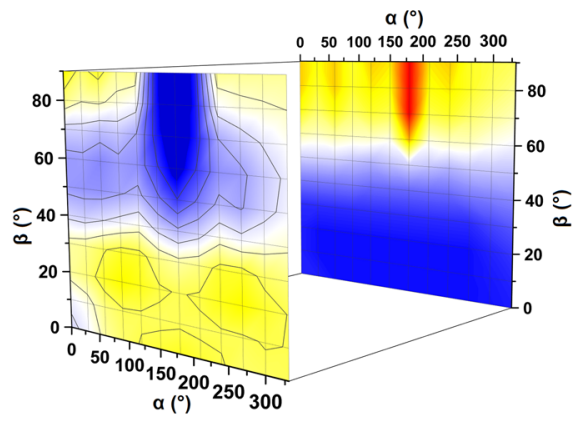

$\alpha\left({ }^{\circ}\right)$
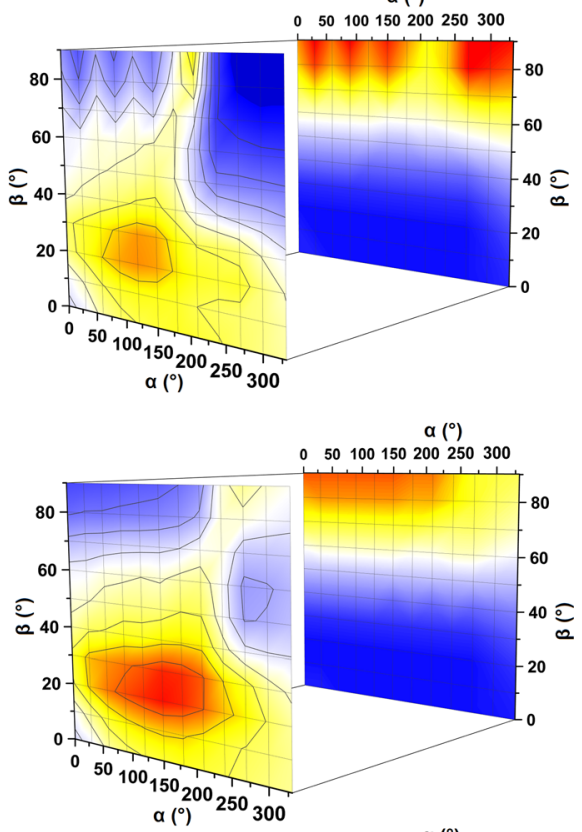

$\begin{array}{ccc} & \alpha\left({ }^{\circ}\right) \\ 0 & 50100150200250300\end{array}$

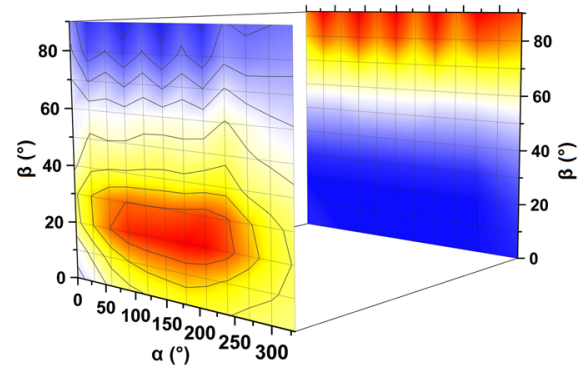

$a\left({ }^{\circ}\right)$

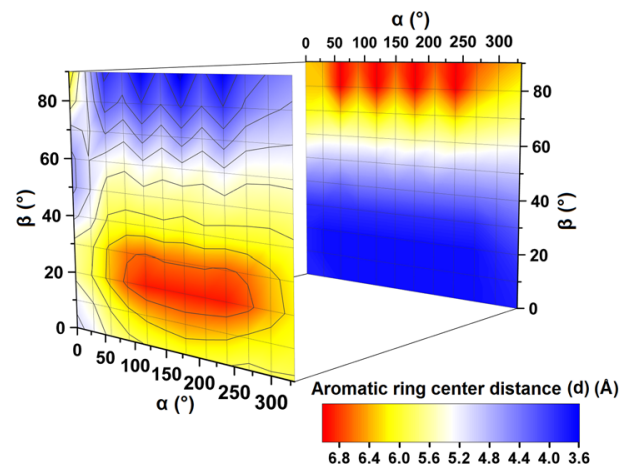

Interaction energy (kcal/mol)

$-3.60-3.00-2.40-1.80-1,20-0.60 \geq 0.00$ 
Fig. 3 PES maps of the studied pyridine dimer systems created on the basis of energy minima found for the systems with the given $\beta$ and $d$ parameter values (1) as well as for the systems with the given $\alpha$ and $\beta$ values (2). These PES maps are shown together with corresponding twist angles between the aromatic rings (1) and the corresponding aromatic ring centers distances (2)

charged and some carbon atoms are positively charged (Fig. 2a). The calculated dipole moment of a pyridine molecule, using M062X/aug-cc-pVTZ, is also relatively high (Fig. 2b).

Investigating the system interaction energy as a function of $d$ and $\beta$ parameters, two main areas associated with energy minima are observed (Fig. 4). The first area corresponds to stacked pyridine dimers and the most stable such configuration was found for $d=3.7 \AA$. In this parallel-displaced configuration (PP1, Fig. 6) one of the rings is twisted around the other about $180^{\circ}$. The second area of energy minima is observed for much larger $d$ and $\beta$ (equal to around $6 \AA$ and $90^{\circ}$, respectively, Fig. 4) and it is associated with two pyridine dimer configurations. In both geometries the pyridine molecules can create hydrogen bonds. In the first case one of the pyridine rings is twisted around the other so two hydrogen bonds could be created (PP2, Fig. 6). In the second one no such twist is observed and only one hydrogen bond is formed (PP3, Fig. 6).

B3LYP-D3BJ interaction energy associated with PP1 is lower (more binding) than those calculated for PP2 and PP3. For PP1 the interaction energy is equal to $-3.68 \mathrm{kcal} \mathrm{mol}^{-1}$. For PP2 and PP3 the interaction energies are similar and they are equal to -2.79 and $-2.80 \mathrm{kcal} \mathrm{mol}^{-1}$, respectively for PP2 and PP3. In PP1 configuration both pyridine molecules are much further from co-planarity than in PP2 and PP3 where both pyridine monomers are co-planar. Being further from coplanarity (a small $\beta$ angle) increases the pyridine interaction surfaces. Hence, the interaction energy in PP1 is dominated by

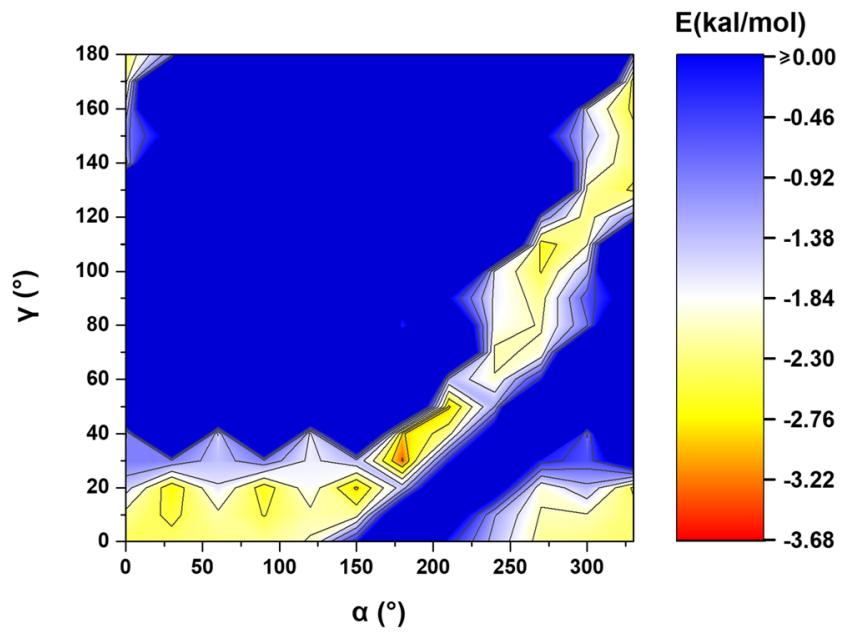

Fig. 5 PES maps of the studied pyridine dimer systems created on the basis of energy minima found for the systems with the given $\alpha$ and $\gamma$ parameters values and for $\beta=90^{\circ}$ and $d=6.1 \AA$

dispersion energy and this energy is the main cause of the binding interaction in this system (Table 2). In PP1 the contribution of electron correlation energy is around three times greater than it is in PP2 and PP3 (Table 2). Unlike in PP1, the interaction energy in PP2 and PP3 is dominated by electrostatic forces with the $E^{\text {ele }}$ about twice the value of $E^{\text {corr }}$. This $E^{\text {ele }}$ term is even slightly higher than it is in PP1. The same is seen for $\mathrm{E}^{\mathrm{pol}}$ terms (Table 2).

Although the interaction energies of approximately 25,000 different pyridine dimers have been calculated, the resolution of the created PES maps was restricted to the selected geometrical parameters (Fig. 2c). The optimization of PP1, PP2, and PP3 resulted in system configurations $\mathrm{PP} 1_{\mathrm{opt}}, \mathrm{PP} 2_{\mathrm{opt}}$, and $\mathrm{PP} 3_{\text {opt }}$, respectively (Fig. 6). The dependencies between the energy terms in the optimized and non-optimized configurations are similar. However, the interaction energies between

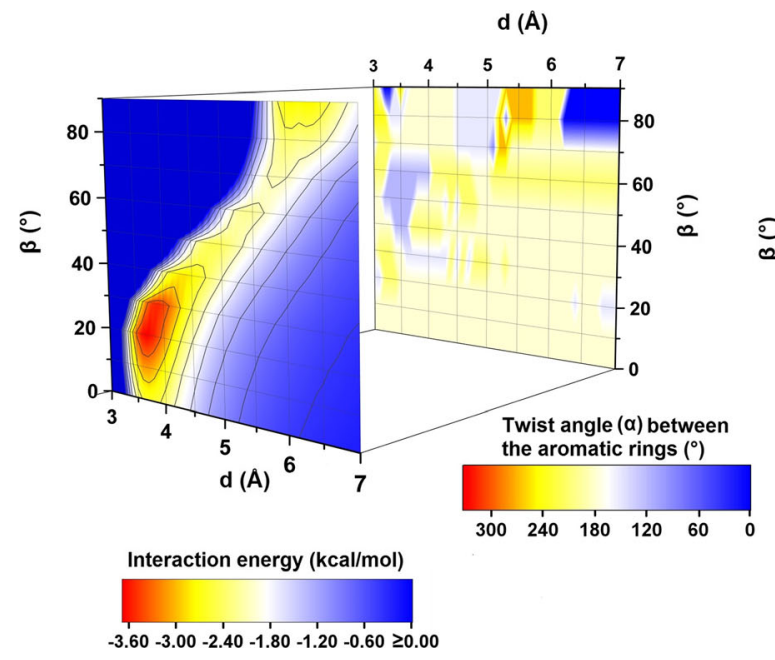

Fig. 4 PES maps of the studied pyridine dimer systems along with the maps depicting the corresponding $\alpha\left(^{\circ}\right)$ and $d(\AA)$ values. The PES maps were created on the basis of energy minima $\left(\mathrm{kcal} \mathrm{mol}^{-1}\right)$ found for the $\alpha\left({ }^{\circ}\right)$

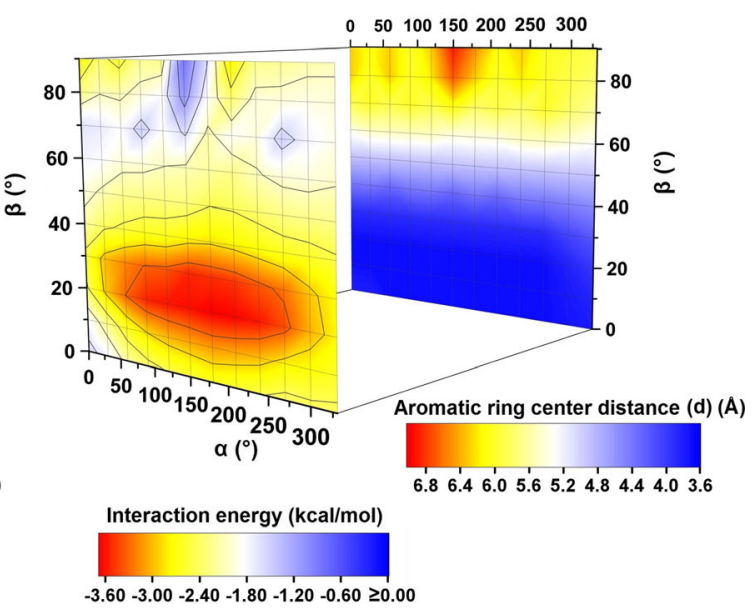

systems with the given $\beta$ and $d$ values (on the left) as well as for the systems with the given $\alpha$ and $\beta$ values (on the right) 
Table 1 The energy minima for the respective $\gamma$ values (in a function of $\beta$ ) found on the basis of PES maps created on the basis of energy minima found for the systems with the given $\beta$ and $d$

\begin{tabular}{lllll}
\hline$\gamma\left({ }^{\circ}\right)$ & $\alpha\left(^{\circ}\right)$ & $\beta\left(^{\circ}\right)$ & $d(\AA)$ & Energy $\left(\mathrm{kcal} \mathrm{mol}^{-1}\right)$ \\
\hline 0 & 180 & 0 & 3.7 & -2.63 \\
& 270 & 20 & 3.7 & -2.78 \\
& 0 & 90 & 6.3 & -2.80 \\
45 & 120 & 20 & 3.7 & -3.16 \\
& 210 & 90 & 6.1 & -2.79 \\
90 & 150 & 20 & 3.7 & -3.62 \\
& 270 & 90 & 6.1 & -2.22 \\
135 & 180 & 20 & 3.7 & -3.68 \\
& 330 & 90 & 6.2 & -2.54 \\
180 & 120 & 20 & 3.7 & -3.59 \\
& 0 & 90 & 6.3 & -2.80 \\
\hline
\end{tabular}

monomers in the former are lower (more binding) compared to those calculated for the latter. The exception is $\mathrm{PP} 3_{\text {opt }}$ with the interaction energy between monomers equal to that in PP3. The biggest difference (around $1 \mathrm{kcal} \mathrm{mol}^{-1}$ ) is seen comparing $\mathrm{PP} 2_{\text {opt }}$ to PP2 (Table 2). As it was found, the interaction energies for hydrogen bonded pyridine molecules strongly depend on $\alpha$ and $\gamma$. Even small changes of these parameters can drastically change the interaction energy-especially when a dimer with two $\mathrm{C}-\mathrm{H} \cdots \mathrm{N}$ hydrogen bonds is considered (Fig. 6). This occurs for $\alpha$ equal to around $180^{\circ}$ and $\gamma$ in the range of $30-40^{\circ}$ (Fig. 5). As $\alpha$ approaches $180^{\circ}$ the second monomer twists so the creation of two identical C-H $\cdots \mathrm{N}$ hydrogen bonds becomes possible - a dimer system with one hydrogen bond is converted to a system with two hydrogen bonds. It is only possible with the increase in $\gamma$. With $\alpha=180^{\circ}$ and $\gamma=0^{\circ}$ both nitrogen atoms face each other which leads to a strong electrostatic repulsion and the binding interaction becomes impossible. With the further increase in $\alpha$ and $\gamma$ a system is converted back to a system with only one C-H $\cdots \mathrm{N}$ hydrogen bond - the rotation angle $(\gamma)$ needs to be adjusted to prevent a system from repulsive $\mathrm{H} \cdot \mathrm{H}$ interactions.

Considering the binding of pyridine molecules in orbital terms, the importance of some interactions associated with the overlap of the molecular orbitals is seen. In PP1 and $\mathrm{PP} 1_{\mathrm{opt}}$ systems, the NBO analysis underlies the importance of $\pi \cdots \pi$ interactions. It has been found that the most significant interactions are between antibonding $\pi$ orbitals present in $\mathrm{C}-\mathrm{N}$ bonds in one monomer with antibonding $\pi$ orbitals in $\mathrm{C}-\mathrm{C}$ bonds in the second monomer (Table 3). These interactions involve the transfer of electron density from antibonding $\pi$ orbitals of C-N bonds in one monomer to antibonding $\pi$ orbitals of $\mathrm{C}$ - $\mathrm{C}$ bonds in the second monomer. This finding may be validated by the performed charge analysis. In PP1 and PP $1_{\text {opt }}$ the charge differences between atoms of $\mathrm{C}-\mathrm{N}$ bonds are slightly higher than they are in a non-interacting pyridine. The same is observed for C-C bonds. In PP1 and PP $1_{\mathrm{opt}}$ they are slightly more polarized than they are in a noninteracting pyridine (Figs. 2a and 6). The estimation of energetic importance of those $\pi$ orbital interactions by second-order perturbation theory (as implemented in NBO) shows that their energy contribution is relatively high. However, it is much higher in PP $1_{\text {opt }}$ than it is in PP1 (Table 3). This suggests that the interactions related to $\pi$ orbitals overlapping (Fig. 7) are highly dependent on geometry. Nevertheless, for those two systems they are a

Table 2 The LMO-EDA decomposed energy terms $\left(\mathrm{kcal} \mathrm{mol}^{-1}\right)$. $* \mathrm{E}^{\mathrm{disp}}$ energy terms were calculated as a difference between the B3LYP-D3BJ/DZ energy and HF/DZ energy

\begin{tabular}{|c|c|c|c|c|c|c|c|c|c|c|c|c|c|c|}
\hline & & & PP1 & & & & & & & PP3 & PP2 & $\mathrm{PP} 1_{\mathrm{opt}}$ & $\mathrm{PP} 2_{\mathrm{opt}}$ & $P P 3_{\text {opt }}$ \\
\hline$\alpha\left(^{\circ}\right)$ & 180.0 & 180.0 & 180.0 & 150.0 & 180.0 & 180.0 & 210.0 & 180.0 & 210.0 & 0.0 & 210.0 & 179.1 & 180.0 & 0.0 \\
\hline$\beta\left(^{\circ}\right)$ & 0.0 & 10.0 & 20.0 & 30.0 & 40.0 & 50.0 & 60.0 & 70.0 & 80.0 & 90.0 & 90.0 & 22.2 & 90.0 & 90.0 \\
\hline$\gamma\left({ }^{\circ}\right)$ & 0.0 & 180.0 & 135.0 & 90.0 & 90.0 & 90.0 & 90.0 & 45.0 & 45.0 & 0.0 & 45.0 & 120.1 & 31.5 & 0.0 \\
\hline $\mathrm{d}(\AA)$ & 3.70 & 3.70 & 3.70 & 3.90 & 4.40 & 4.90 & 5.40 & 5.80 & 6.00 & 6.30 & 6.10 & 3.62 & 5.74 & 6.24 \\
\hline $\mathrm{E}^{\text {ele }}$ & -1.29 & -1.80 & -2.83 & -3.23 & -2.67 & -2.61 & -2.25 & -2.20 & -3.27 & -3.81 & -3.94 & -3.99 & -6.41 & -4.08 \\
\hline $\mathrm{E}^{\mathrm{ex}}$ & -8.17 & -9.22 & -11.95 & -11.82 & -8.21 & -6.87 & -5.19 & -4.37 & -6.05 & -6.27 & -6.53 & -15.35 & -11.31 & -7.01 \\
\hline$E^{\text {rep }}$ & 13.05 & 14.55 & 18.80 & 18.72 & 13.22 & 11.19 & 8.53 & 7.20 & 10.02 & 10.43 & 10.84 & 24.44 & 18.86 & 11.70 \\
\hline$E^{e x}+E^{r e p}$ & 4.88 & 5.33 & 6.85 & 6.90 & 5.01 & 4.32 & 3.34 & 2.83 & 3.97 & 4.16 & 4.31 & 9.09 & 7.55 & 4.69 \\
\hline $\mathrm{E}^{\mathrm{pol}}$ & -0.30 & -0.43 & -0.72 & -0.73 & -0.52 & -0.44 & -0.39 & -0.48 & -1.02 & -1.22 & -1.21 & $-0 / 94$ & -1.97 & -1.33 \\
\hline$E^{\text {disp* }}$ & -5.92 & -6.22 & -6.97 & -6.48 & -4.39 & -3.74 & -2.83 & -2.28 & -2.04 & -1.93 & -1.95 & -8.03 & -3.09 & -2.08 \\
\hline $\mathrm{HF} / \mathrm{DZ}$ & 3.29 & 3.10 & 3.29 & 2.94 & 1.81 & 1.27 & 0.71 & 0.16 & -0.31 & -0.87 & -0.84 & 4.16 & -0.83 & -0.72 \\
\hline B3LYP-D3BJ/DZ & -2.63 & -3.12 & -3.68 & -3.54 & -2.58 & -2.47 & -2.24 & -2.12 & -2.35 & -2.80 & -2.79 & -3.87 & -3.92 & -2.80 \\
\hline
\end{tabular}

The results are shown for the systems corresponding to energy minima found for the given $\beta$ as well as for PP1, PP2, PP3, PP $1_{\mathrm{opt}}, \mathrm{PP} 2_{\mathrm{opt}}$, and PP $3_{\mathrm{opt}}$ configurations 

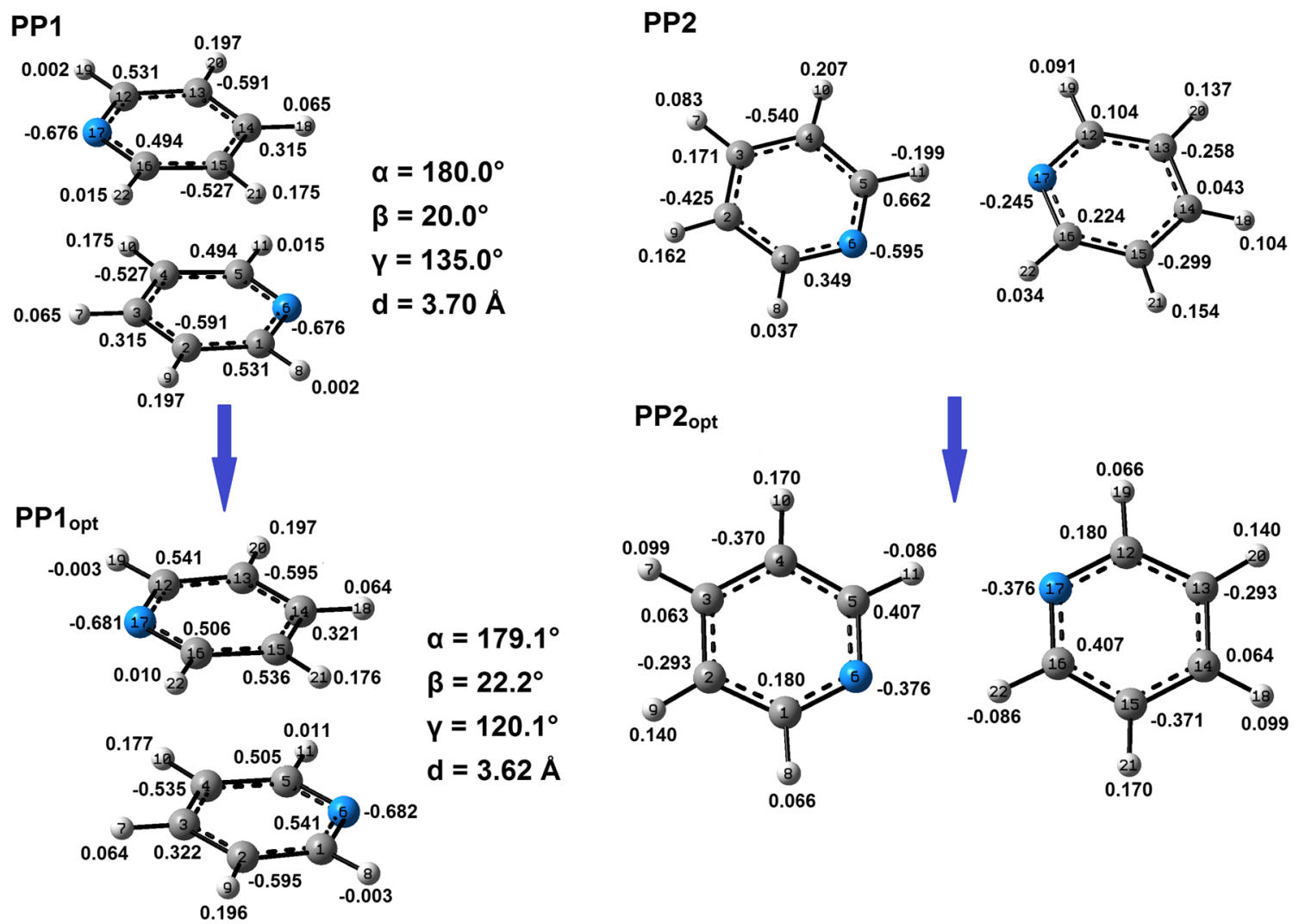

$$
\begin{aligned}
& \alpha=210.0^{\circ} \\
& \beta=90.0^{\circ} \\
& Y=45.0^{\circ} \\
& d=6.10 \AA
\end{aligned}
$$
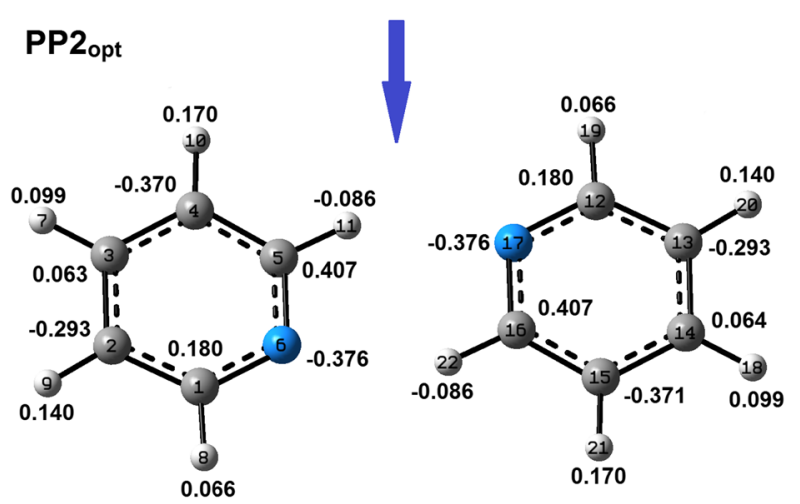

$$
\alpha=180.0^{\circ}
$$

$\beta=90.0^{\circ}$

$Y=31.5^{\circ}$

$d=5.74 \AA$
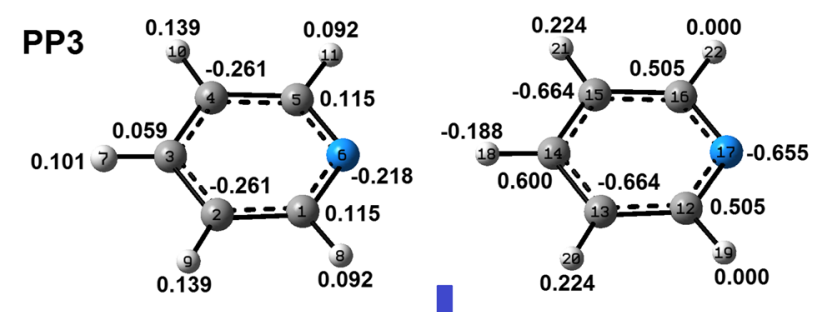

$$
\begin{aligned}
& \alpha=0.0^{\circ} \\
& \beta=90.0^{\circ} \\
& Y=0.0^{\circ} \\
& d=6.30 \AA
\end{aligned}
$$
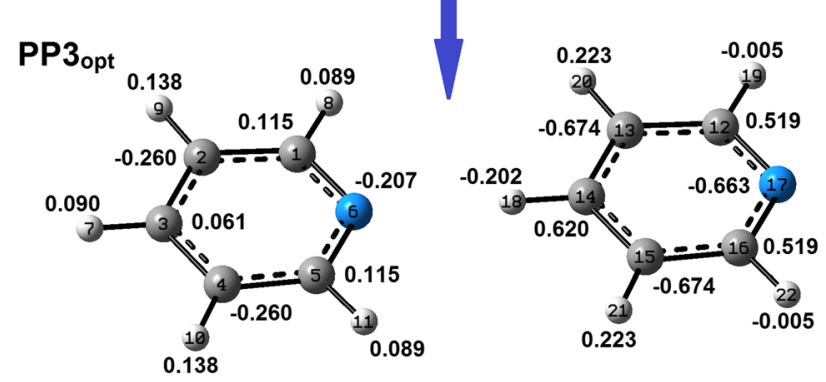

$$
\begin{aligned}
& \alpha=0.0^{\circ} \\
& \beta=90.0^{\circ} \\
& Y=0.0^{\circ} \\
& d=6.24 \AA
\end{aligned}
$$

Fig. 6 Geometries of the pyridine-pyridine systems that are associated with the found energy minima, together with the atom HLY charge values (e) and the atom numbering scheme (integers) used in NBO analysis.
$\mathrm{PP} 1_{\text {opt }}, \mathrm{PP} 2_{\text {opt }}$, and $\mathrm{PP} 3_{\text {opt }}$ are the configurations that resulted from the optimization of PP1, PP2, and PP3 systems significant source of the binding interactions - direct interactions between the respective molecular $\pi$ orbitals add an extra energy (Table 3) making the interactions between the pyridine monomers the binding one. Other $\pi$ orbital interactions (e.g., the ones associated with the transfer of electron density from bonding $\pi$ orbitals of $\mathrm{C}-\mathrm{C}$ bonds in one monomer to antibonding $\pi$ orbitals of $\mathrm{C}-\mathrm{C}$ bonds in the second monomer) are present as well but they are less significant (Table 3).

For PP2, PP3, PP $2_{\text {opt }}$, and PP $3_{\text {opt }}$ systems, the NBO analysis validates the creation of $\mathrm{C}-\mathrm{H} \cdots \mathrm{N}$ hydrogen bonds (Table 3). The main source of the interactions involves the 
Table 3 The second order perturbative estimates of donor-acceptor interactions in the NBO basis for the selected pyridine dimer systems

\begin{tabular}{|c|c|c|c|c|}
\hline \multicolumn{2}{|c|}{ Donor unit } & \multicolumn{2}{|c|}{ Acceptor unit } & \multirow{2}{*}{$\begin{array}{l}\text { Stabilization energy } \\
\left(\mathrm{kcal} \mathrm{mol}^{-1}\right)\end{array}$} \\
\hline Type & Donor NBO & Type & Acceptor NBO & \\
\hline \multicolumn{5}{|l|}{ PP1 } \\
\hline$\pi$ & $\mathrm{C} 1-\mathrm{C} 2$ & $\pi^{*}$ & $\mathrm{C} 14-\mathrm{C} 15$ & 0.32 \\
\hline$\pi$ & C5-N6 & $\pi^{*}$ & $\mathrm{C} 14-\mathrm{C} 15$ & 0.22 \\
\hline$\pi^{*}$ & C5-N6 & $\pi^{*}$ & $\mathrm{C} 12-\mathrm{C} 13$ & 1.26 \\
\hline$\pi^{*}$ & C5-N6 & $\pi^{*}$ & $\mathrm{C} 14-\mathrm{C} 15$ & 1.08 \\
\hline$\pi$ & $\mathrm{C} 12-\mathrm{C} 13$ & $\pi^{*}$ & $\mathrm{C} 3-\mathrm{C} 4$ & 0.32 \\
\hline$\pi$ & C16-N17 & $\pi^{*}$ & $\mathrm{C} 3-\mathrm{C} 4$ & 0.22 \\
\hline$\pi^{*}$ & C16-N17 & $\pi^{*}$ & $\mathrm{C} 1-\mathrm{C} 2$ & 1.26 \\
\hline$\pi^{*}$ & C16-N17 & $\pi^{*}$ & $\mathrm{C} 3-\mathrm{C} 4$ & 1.08 \\
\hline \multicolumn{5}{|c|}{$\mathrm{PP} 1_{\mathrm{opt}}$} \\
\hline$\pi$ & $\mathrm{C} 3-\mathrm{C} 4$ & $\pi^{*}$ & C16-N17 & 0.24 \\
\hline$\pi$ & $\mathrm{C} 1-\mathrm{C} 2$ & $\pi^{*}$ & $\mathrm{C} 14-\mathrm{C} 15$ & 0.37 \\
\hline$\pi^{*}$ & C5-N6 & $\pi^{*}$ & $\mathrm{C} 12-\mathrm{C} 13$ & 1.34 \\
\hline$\pi^{*}$ & C5-N6 & $\pi^{*}$ & $\mathrm{C} 14-\mathrm{C} 15$ & 1.90 \\
\hline$\pi$ & $\mathrm{C} 12-\mathrm{C} 13$ & $\pi^{*}$ & $\mathrm{C} 3-\mathrm{C} 4$ & 0.36 \\
\hline$\pi$ & $\mathrm{C} 14-\mathrm{C} 15$ & $\pi^{*}$ & C5-N6 & 0.23 \\
\hline$\pi^{*}$ & C16-N17 & $\pi^{*}$ & $\mathrm{C} 1-\mathrm{C} 2$ & 1.24 \\
\hline$\pi^{*}$ & C16-N17 & $\pi^{*}$ & $\mathrm{C} 3-\mathrm{C} 4$ & 2.05 \\
\hline \multicolumn{5}{|l|}{ PP2 } \\
\hline lp & N6 & ry* & $\mathrm{H} 22$ & 0.39 \\
\hline lp & N17 & $\sigma^{*}$ & C5-H11 & 2.48 \\
\hline \multicolumn{5}{|c|}{$\mathrm{PP} 2_{\text {opt }}$} \\
\hline lp & N6 & ry* & $\mathrm{H} 22$ & 0.20 \\
\hline lp & N6 & $\sigma^{*}$ & $\mathrm{C} 16-\mathrm{H} 22$ & 2.08 \\
\hline lp & N17 & ry* & H11 & 0.20 \\
\hline lp & N17 & $\sigma^{*}$ & C5-H11 & 2.07 \\
\hline \multicolumn{5}{|l|}{ PP3 } \\
\hline lp & N6 & $\sigma^{*}$ & C14-H18 & 2.62 \\
\hline$\sigma$ & C14-H18 & ry* & N6 & 0.24 \\
\hline \multicolumn{5}{|c|}{$\mathrm{PP} 3_{\text {opt }}$} \\
\hline lp & N6 & $\sigma^{*}$ & C14-H18 & 2.97 \\
\hline$\sigma$ & C14-H18 & ry* & N6 & 0.27 \\
\hline
\end{tabular}

Only the interactions of energy equal to at least $0.2 \mathrm{kcal} \mathrm{mol}^{-1}$ were included. The asterix (*) stands for an antibonding orbital; lp - lone electron pair; ry - Rydberg orbital

orbital interactions utilizing nitrogen's lone electron pairs and antibonding orbitals of the respective $\mathrm{C}-\mathrm{H}$ bonds: the electron density of lone electron pairs of nitrogen atoms is transferred to the antibonding orbitals of the respective $\mathrm{C}-\mathrm{H}$ bonds (Table 3, Fig. 7). HLY charge fitting method confirms this finding. Compared to a non-interacting pyridine, in PP2, PP3, PP $2_{\text {opt }}$ and PP $3_{\text {opt }}$ systems nitrogen atoms are less negative while the respective hydrogen atoms (taking part in formation of hydrogen bonds) are negative instead of being positive as it is in a non-interacting pyridine molecule (Fig. 6).

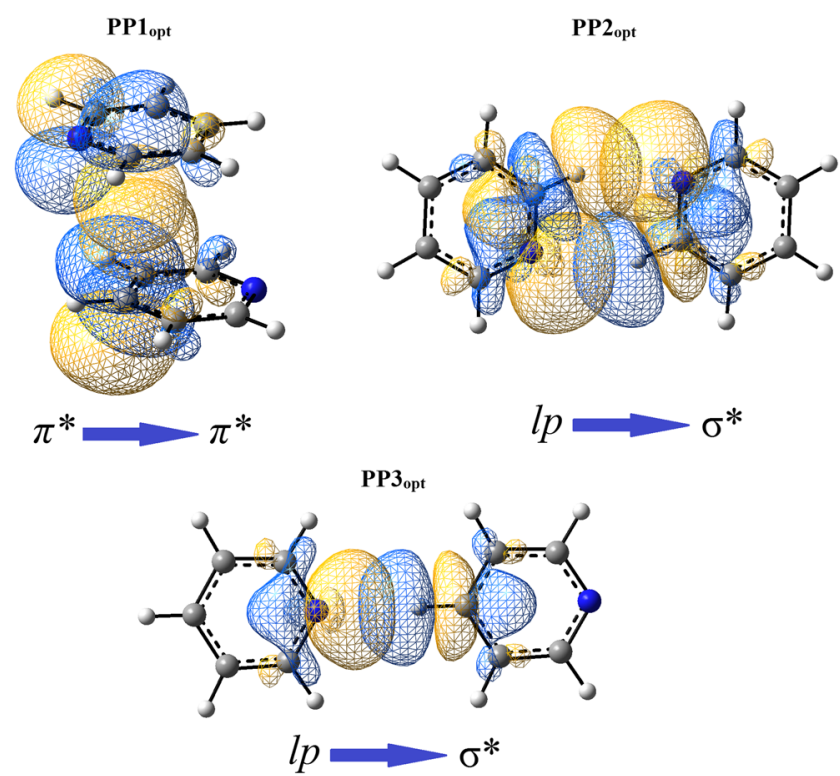

Fig. $7 \mathrm{PP} 1_{\text {opt }}, \mathrm{PP} 2_{\text {opt }}$, and $\mathrm{PP} 3_{\text {opt }}$ configurations of pyridine dimers with the selected NBO orbitals (drawn with the isovalue equal to $0.015 \mathrm{au}$ ) taking part in the intermolecular interactions

With the increase in $d$, the maximum binding energy for that $d$ is observed for a system configuration with higher $\beta$. It is related to the maximization of dispersion forces. Keeping the same $d$, the increase in $\beta$ causes the decrease in the distance between surfaces of the interacting molecules. Moving from stacked to hydrogen bonded systems via $d$ and $\beta$ parameters the changes of $\gamma$ angle are observed (Table 2, Fig. 8). The higher $d$ and $\beta$ parameters are, the smaller $\gamma$ becomes (Table 2). Similarly, with the increase in $d$ and $\beta$ angles, the contribution of electron correlation energy gets smaller (Table 2). This is related to the decrease of the monomer interaction surfaces. Hence, going to hydrogen bonded systems involves the increase of the interaction energy between the monomers and the interaction energy gets less binding. Though the increase of the interaction energy is observed it does not get higher than $-2 \mathrm{kcal} \mathrm{mol}^{-1}$ (Fig. 8). This increase is observed till $\beta$ gets close to $70^{\circ}$. After this point (with $\beta$ equal to around $70^{\circ}$ ) the interaction energy between the monomers starts getting smaller (Table 2, Fig. 8) which is explained by the creation of $\mathrm{C}-\mathrm{H} \cdots \mathrm{N}$ hydrogen bond/bonds.

Analyzing the system interaction energy as a function of $\alpha$ and $\beta$ parameters (the systems that correspond to energy minima found for the given $\alpha$ and $\beta$ values) one main energy minimum is found (Fig. 4). This minimum is quite broad and this enables a certain degree of flexibility in constructing the system configuration of minimum binding energy. This area is within a $\beta$ range of $20-30^{\circ}$ and within an $\alpha$ range of $60-270^{\circ}$. The interaction energies between pyridine monomers in it are very small and they are close to $-3.6 \mathrm{kcal} \mathrm{mol}^{-}$ ${ }^{1}$ (Figs. 4 and 9). The distances between the monomer centroids are similar to each other and are within the range 3.7- 
Fig. 8 Interaction energy curve created on the basis of data corresponding to energy minima found for the systems with the given $\beta$. The system configurations are presented in the picture. The curve was created using splicing interpolation

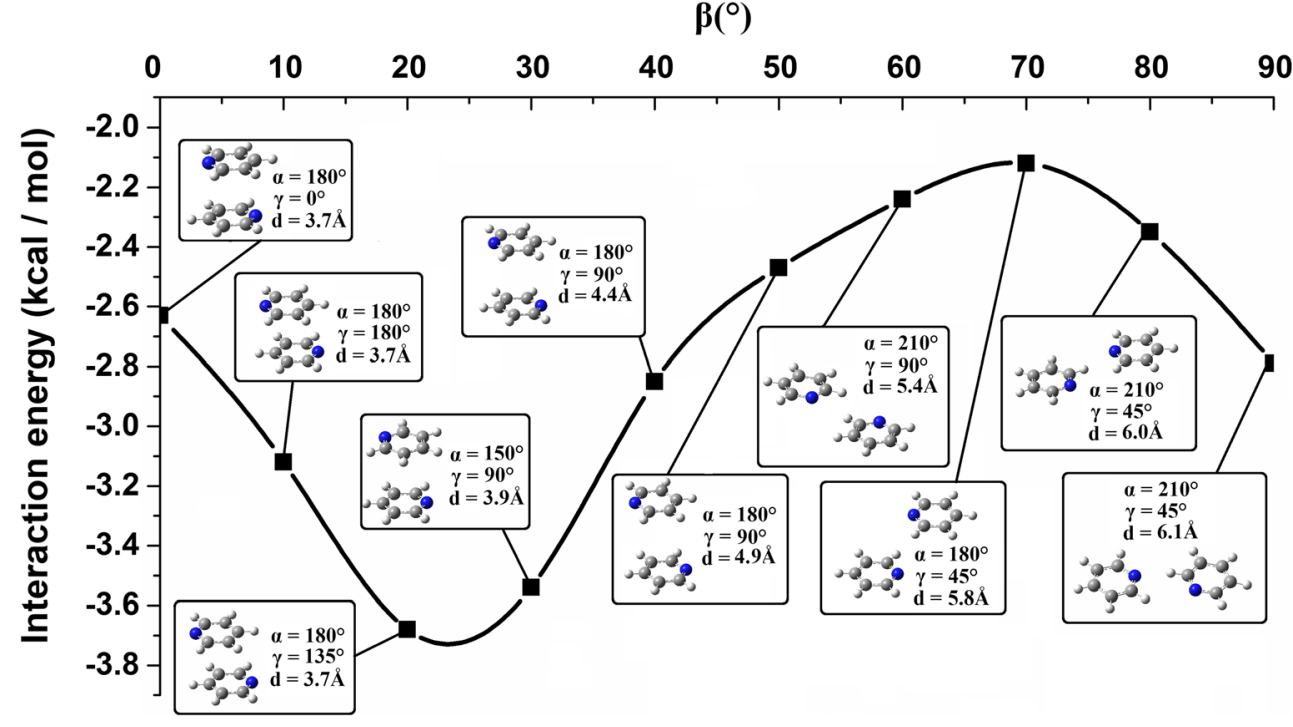

$3.9 \AA$ (Table 4). The $\gamma$ parameters correlate with $\alpha$ : going through systems associated with energy minima found for the given $\alpha$, the energy minimization for a system with higher $\alpha$ is achieved by the increase of $\gamma$ (Table 4, Fig. 9). The decrease of the system energy is achieved by a molecular arrangement in which there is an optimal balance between the electrostatic and dispersion forces. When a pyridine dimer geometry is kept within some geometrical boundaries, like for example $d$ and $\beta$ (Figs. 4 and 9), the maintenance of the system energy may be achieved by changing other parameters. It is possible to result in a parallel-displaced system configuration possessing similar energy but with different twists and rotation angles. In all the systems corresponding to energy minima found for the given $\alpha$, the contribution of electron correlation energy is dominant, and it is around 2.5 times the value of electrostatic energy (Table 4). $\mathrm{E}^{\text {pol }}$ terms in those systems are similar and they are equal to around $-0.7 \mathrm{kcal}$ $\mathrm{mol}^{-1}$. In their case, as it was in PP1 and PP $1_{\mathrm{opt}}$, the importance of $\pi \cdots \pi$ orbital interactions is shown. Again, as found for PP1 and PP $1_{\text {opt }}$, these interactions involve the transfer of electron density from antibonding $\pi$ orbitals of $\mathrm{C}-\mathrm{N}$ bonds in one monomer to antibonding $\pi$ orbitals of $\mathrm{C}-\mathrm{C}$ bonds in the second monomer. Other $\pi$ orbital interactions (e.g., the ones associated with the transfer of electron density from bonding $\pi$ orbitals of $\mathrm{C}-\mathrm{C}$ bonds in one monomer to antibonding $\pi$ orbitals of $\mathrm{C}-\mathrm{C}$ bonds in the second monomer) are less important. The most significant $\pi$ orbital interactions (possessing the highest stabilization energies) are observed for configurations with the twist angle in the range $120-300^{\circ}$ (Table 1 in the Supporting information). A special role of the $\pi$ orbitals in
Fig. 9 Interaction energy curve created on the basis of data corresponding to energy minima found for the systems with the given $\alpha$. The system configurations are presented in the picture. The curve was created using splicing interpolation

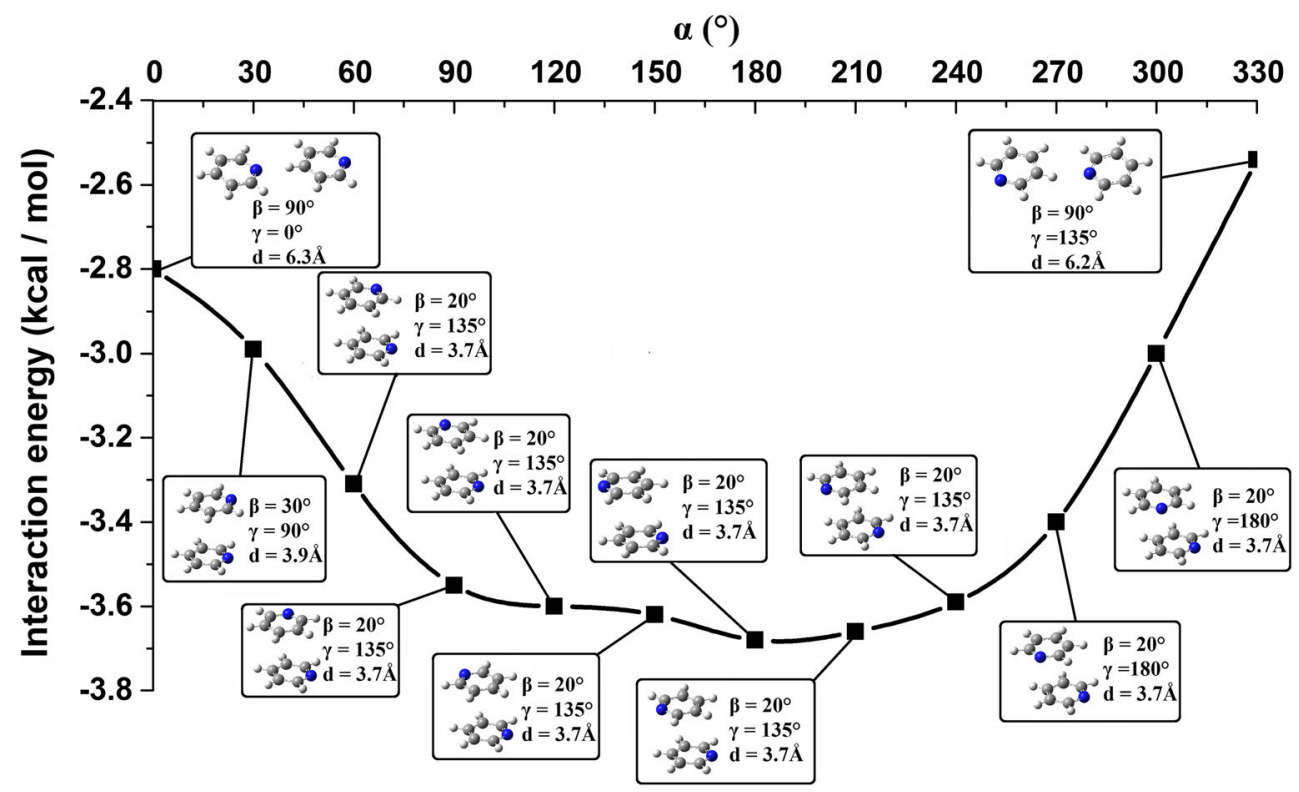


Table 4 The LMO-EDA decomposed energy terms $\left(\mathrm{kcal} \mathrm{mol}^{-1}\right) . * \mathrm{E}^{\mathrm{disp}}$ energy terms were calculated as a difference between the B3LYP-D3BJ/DZ energy and HF/DZ energy

\begin{tabular}{|c|c|c|c|c|c|c|c|c|c|c|c|c|}
\hline$\alpha\left(^{\circ}\right)$ & 0 & 30 & 60 & 90 & 120 & 150 & 180 & 210 & 240 & 270 & 300 & 330 \\
\hline$\beta\left({ }^{\circ}\right)$ & 90 & 30 & 20 & 20 & 20 & 20 & 20 & 20 & 20 & 20 & 20 & 90 \\
\hline$\gamma\left({ }^{\circ}\right)$ & 0 & 90 & 135 & 135 & 135 & 135 & 135 & 135 & 180 & 180 & 180 & 135 \\
\hline $\mathrm{d}(\AA)$ & 6.3 & 3.9 & 3.7 & 3.7 & 3.7 & 3.7 & 3.7 & 3.7 & 3.7 & 3.7 & 3.7 & 6.2 \\
\hline$E^{\text {ele }}$ & -3.81 & -2.70 & -2.39 & -2.64 & -2.73 & -2.80 & -2.83 & -2.72 & -2.68 & -2.44 & -2.05 & -2.70 \\
\hline$E^{e x}$ & -6.27 & -11.96 & -11.66 & -11.95 & -12.19 & -12.25 & -11.95 & -11.64 & -12.04 & -11.82 & -11.64 & -5.28 \\
\hline $\mathrm{E}^{\mathrm{rep}}$ & 10.43 & 18.97 & 18.34 & 18.77 & 19.17 & 19.27 & 18.80 & 18.29 & 18.92 & 18.60 & 18.34 & 8.67 \\
\hline$E^{e x}+E^{r e p}$ & 4.16 & 7.01 & 6.68 & 6.82 & 6.98 & 7.02 & 6.85 & 6.65 & 6.88 & 6.78 & 6.70 & 3.39 \\
\hline $\mathrm{E}^{\mathrm{pol}}$ & -1.22 & -0.71 & -0.69 & -0.75 & -0.77 & -0.75 & -0.72 & -0.70 & -0.75 & -0.72 & -0.67 & -0.95 \\
\hline $\mathrm{E}^{\mathrm{disp} *}$ & -1.93 & -6.58 & -6.91 & -6.98 & -7.08 & -7.08 & -6.97 & -6.89 & -7.04 & -7.02 & -6.99 & -2.29 \\
\hline $\mathrm{HF} / \mathrm{DZ}$ & -0.87 & 3.59 & 3.60 & 3.43 & 3.48 & 3.46 & 3.29 & 3.23 & 3.45 & 3.62 & 3.99 & -0.25 \\
\hline B3LYP-D3BJ/DZ & -2.80 & -2.99 & -3.31 & -3.55 & -3.60 & -3.62 & -3.68 & -3.66 & -3.59 & -3.40 & -3.00 & -2.54 \\
\hline
\end{tabular}

The results are shown for the systems corresponding to energy minima found for the given $\alpha$

molecular stacking was brought up by Grimme in his work "Do special noncovalent $\pi-\pi$ stacking interactions really exist?" [71]. It has been concluded that caution is required describing the effect of $\pi$-systems in chemical or biological systems such as stacked nucleobases since the interaction energies of small systems possessing one or two rings, for both aromatic and saturated compounds, are very similar [71]. In another study [72], the orbital interactions in stacked systems were examined in terms of qualitative analysis of the overlap of the monomer densities providing a more intuitive picture of the interaction [72]. In the present study however, NBO analysis has enabled creation a "quantitative picture" of pyridine orbital interactions showing their important role in intermolecular bonding.

The changes of the interaction energy in a function of $d$ and $\beta$ parameters observed for different $\gamma$ parameters (corresponding to energy minima found for the given $\alpha$ and $\beta$ and for the given $\gamma$ ) are similar to each other (Fig. 3). They are also similar to the changes observed on the basis of the analysis covering all the calculated systems (Fig. 4). In the case of each $\gamma$ angle, two areas of energy minima are observed (Fig. 3). The first one is seen for smaller $d$ (in the range of 3.5-4.0 $\AA$ ) and for smaller $\beta$ (in the range of $0-30^{\circ}$ ). The second is seen for bigger $d$ (in the range of 5.5-7.0 $\AA$ ) and for bigger $\beta$ (in the range of $70-90^{\circ}$ ). The first area includes the energy minimum associated with a stacked configuration and for each rotation angle it was found for the same $\beta$ and $d$ (Table 1). The interaction energy for this minimum gets more binding as $\gamma$ approaches $135^{\circ}$. The $\alpha$ for this minimum changes as well and it gets bigger as $\gamma$ approaches $135^{\circ}$ (Table 1). An exception is found for $\gamma=0^{\circ}$ for which this energy minimum exists for $\alpha=270^{\circ}$. The reason for these different twist angle values is the maximization of the electrostatic binding forces. The second area of energy minima is associated with the formation of C-H $\cdots \mathrm{N}$ hydrogen bonds (Table 3, Fig. 6).
Comparing PES maps depicting the interaction energy as a function of $\alpha$ and $\beta$ parameters that were made separately for each rotation angle (each PES map corresponds to the interaction energies calculated for the given $\gamma$ ) some differences are seen. Different $\gamma$ angles force different geometrical arrangements of the interacting monomers (e.g., two systems with the same $\alpha$ but with different $\gamma$ may have configurations with a different distance between nitrogen atoms). However, apart from some differences found for the obtained PES maps, when a stacked geometry is considered, the optimal $\beta$ and $d$ for each $\gamma$ appeared to be $20^{\circ}$ and $3.7 \AA$, respectively for $\beta$ and $d$ (Table 5). The same was observed for the analysis based on $d$ and $\beta$ parameters (Fig. 3, Table 1). For those $\beta$ and

Table 5 The energy minima for the respective $\gamma$ values (in a function of $\alpha$ ) found on the basis of PES maps created on the basis of energy minima found for the systems with the given $\alpha$ and $\beta$

\begin{tabular}{lllll}
\hline$\gamma\left({ }^{\circ}\right)$ & $\alpha\left(^{\circ}\right)$ & $\beta\left(^{\circ}\right)$ & $d(\AA)$ & Energy $\left(\mathrm{kcal} \mathrm{mol}{ }^{-1}\right)$ \\
\hline 0 & 0 & 90 & 6.3 & -2.80 \\
& 90 & 20 & 3.7 & -2.78 \\
& 180 & 0 & 3.7 & -2.63 \\
45 & 270 & 20 & 3.7 & -2.78 \\
& 120 & 20 & 3.7 & -3.16 \\
90 & 150 & 20 & 3.7 & -3.62 \\
135 & 180 & 20 & 3.7 & -3.68 \\
180 & 0 & 90 & 6.3 & -2.80 \\
& 120 & 20 & 3.7 & -3.59 \\
& 150 & 20 & 3.7 & -3.59 \\
& 180 & 20 & 3.7 & -3.59 \\
& 210 & 20 & 3.7 & -3.59 \\
& 540 & 20 & 3.7 & -3.59 \\
\hline
\end{tabular}


Table 6 The second order perturbative estimates of donor-acceptor interactions in the NBO basis for systems corresponding to energy minima found for the systems with the given $\alpha$ values and with $\beta=60^{\circ}$ and for $\gamma=0^{\circ}$

\begin{tabular}{|c|c|c|c|c|}
\hline \multicolumn{2}{|c|}{ Donor unit } & \multicolumn{2}{|c|}{ Acceptor unit } & \multirow{2}{*}{$\begin{array}{l}\text { Stabilization energy } \\
\left(\mathrm{kcal} \mathrm{mol}^{-1}\right)\end{array}$} \\
\hline Type & Donor NBO & Type & Acceptor NBO & \\
\hline \multicolumn{5}{|c|}{$\alpha=0^{\circ}, \mathrm{d}=5.6 \AA$} \\
\hline $1 \mathrm{p}$ & N6 & $\pi^{*}$ & $\mathrm{C} 14-\mathrm{C} 15$ & 0.20 \\
\hline$\pi^{*}$ & $\mathrm{C} 1-\mathrm{N} 6$ & $\pi^{*}$ & $\mathrm{C} 14-\mathrm{C} 15$ & 0.28 \\
\hline \multicolumn{5}{|c|}{$\alpha=30^{\circ}, \mathrm{d}=5.5 \AA$} \\
\hline$\pi^{*}$ & C5-N6 & $\pi^{*}$ & $\mathrm{C} 13-\mathrm{C} 14$ & 0.30 \\
\hline \multicolumn{5}{|c|}{$\alpha=60^{\circ}, \mathrm{d}=5.6 \AA$} \\
\hline$\pi^{*}$ & C5-N6 & $\pi^{*}$ & $\mathrm{C} 14-\mathrm{C} 15$ & 0.25 \\
\hline \multicolumn{5}{|c|}{$\alpha=90^{\circ}, \mathrm{d}=5.5 \AA$} \\
\hline$\pi^{*}$ & $\mathrm{C} 5-\mathrm{N} 6$ & $\pi^{*}$ & $\mathrm{C} 14-\mathrm{C} 15$ & 0.32 \\
\hline \multicolumn{5}{|c|}{$\alpha=120^{\circ}, \mathrm{d}=5.5 \AA$} \\
\hline lp & N6 & $\pi^{*}$ & C16-N17 & 0.25 \\
\hline$\pi^{*}$ & $\mathrm{C} 5-\mathrm{N} 6$ & $\pi^{*}$ & $\mathrm{C} 16-\mathrm{N} 17$ & 1.38 \\
\hline \multicolumn{5}{|c|}{$\alpha=150^{\circ}, \mathrm{d}=5.4 \AA$} \\
\hline$\pi^{*}$ & $\mathrm{C} 5-\mathrm{N} 6$ & $\pi^{*}$ & $\mathrm{C} 15-\mathrm{C} 16$ & 0.58 \\
\hline \multicolumn{5}{|c|}{$\alpha=180^{\circ}, \mathrm{d}=6.4 \AA$} \\
\hline \multicolumn{5}{|c|}{ no interaction of energy equals to at least $0.2 \mathrm{kcal} \mathrm{mol}^{-1}$} \\
\hline \multicolumn{5}{|c|}{$\alpha=210^{\circ}, \mathrm{d}=5.4 \AA$} \\
\hline$\pi^{*}$ & $\mathrm{C} 1-\mathrm{N} 6$ & $\pi^{*}$ & $\mathrm{C} 12-\mathrm{C} 13$ & 0.59 \\
\hline \multicolumn{5}{|c|}{$\alpha=240^{\circ}, \mathrm{d}=5.5 \AA$} \\
\hline $1 \mathrm{p}$ & N6 & $\pi^{*}$ & $\mathrm{C} 12-\mathrm{N} 17$ & 0.26 \\
\hline$\pi^{*}$ & $\mathrm{C} 1-\mathrm{N} 6$ & $\pi^{*}$ & $\mathrm{C} 12-\mathrm{N} 17$ & 1.38 \\
\hline \multicolumn{5}{|c|}{$\alpha=270^{\circ}, \mathrm{d}=5.5 \AA$} \\
\hline$\pi^{*}$ & $\mathrm{C} 1-\mathrm{N} 6$ & $\pi^{*}$ & $\mathrm{C} 13-\mathrm{C} 14$ & 0.32 \\
\hline \multicolumn{5}{|c|}{$\alpha=300^{\circ}, \mathrm{d}=5.6 \AA$} \\
\hline$\pi^{*}$ & $\mathrm{C} 1-\mathrm{N} 6$ & $\pi^{*}$ & $\mathrm{C} 13-\mathrm{C} 14$ & 0.25 \\
\hline \multicolumn{5}{|c|}{$\alpha=330^{\circ}, \mathrm{d}=5.5 \AA$} \\
\hline$\pi^{*}$ & $\mathrm{C} 1-\mathrm{N} 6$ & $\pi^{*}$ & $\mathrm{C} 14-\mathrm{C} 15$ & 0.30 \\
\hline
\end{tabular}

Only the interactions of energy equal to at least $0.2 \mathrm{kcal} \mathrm{mol}^{-1}$ were included. The asterix (*) stands for an antibonding orbital; lp - lone electron pair

Table 7 The LMO-EDA decomposed energy terms $\left(\mathrm{kcal} \mathrm{mol}^{-1}\right)$. ${ }^{\mathrm{E}}{ }^{\text {disp }}$ energy terms were calculated as a difference between the B3LYP-D3BJ/DZ energy and HF/DZ energy

\begin{tabular}{|c|c|c|c|c|c|c|c|c|c|c|c|c|}
\hline$\alpha\left(^{\circ}\right)$ & 0 & 30 & 60 & 90 & 120 & 150 & 180 & 210 & 240 & 270 & 300 & 330 \\
\hline $\mathrm{d}(\AA)$ & 5.6 & 5.5 & 5.6 & 5.5 & 5.5 & 5.4 & 6.4 & 5.4 & 5.5 & 5.5 & 5.6 & 5.5 \\
\hline$E^{\text {ele }}$ & -0.32 & -0.16 & -0.14 & -0.21 & -0.38 & 0.63 & 1.11 & 0.63 & -0.39 & -0.21 & -0.14 & -0.16 \\
\hline $\mathrm{E}^{\mathrm{ex}}$ & -2.78 & -3.17 & -2.89 & -3.01 & -3.14 & -3.05 & -0.09 & -3.05 & -3.14 & -3.01 & -2.89 & -3.17 \\
\hline $\mathrm{E}^{\mathrm{rep}}$ & 4.47 & 5.04 & 4.63 & 4.78 & 5.06 & 4.83 & 0.14 & 4.83 & 5.06 & 4.78 & 4.63 & 5.04 \\
\hline $\mathrm{E}^{\mathrm{ex}}+\mathrm{E}^{\mathrm{rep}}$ & 1.69 & 1.87 & 1.74 & 1.77 & 1.92 & 1.78 & 0.05 & 1.78 & 1.92 & 1.77 & 1.74 & 1.87 \\
\hline $\mathrm{E}^{\mathrm{pol}}$ & -0.30 & -0.29 & -0.29 & -0.28 & -0.34 & -0.35 & -0.07 & -0.35 & -0.34 & -0.28 & -0.29 & -0.29 \\
\hline$E^{\text {disp* }}$ & -2.17 & -2.55 & -2.29 & -2.41 & -2.23 & -2.50 & -0.82 & -2.50 & -2.23 & -2.41 & -2.29 & -2.55 \\
\hline $\mathrm{HF} / \mathrm{DZ}$ & 1.07 & 1.42 & 1.31 & 1.28 & 1.19 & 2.06 & 1.10 & 2.06 & 1.19 & 1.28 & 1.31 & 1.42 \\
\hline B3LYP-D3BJ/DZ & -1.1 & -1.13 & -0.98 & -1.13 & -1.04 & -0.44 & 0.28 & -0.44 & -1.04 & -1.13 & -0.98 & -1.13 \\
\hline
\end{tabular}

The results are shown for systems corresponding to energy minima found for the selected systems with $\beta=60^{\circ}$ (on the basis of PES created in a function of $\alpha$ and $\beta$ parameters for $\gamma=0^{\circ}$ ) 
Fig. 10 Selected configurations of pyridine dimers where the formation of $\mathrm{C}-\mathrm{H} \cdots \pi$ interactions might be proposed. The selected NBO orbitals (drawn with the isovalue equal to $0.015 \mathrm{au}$ ) taking part in the intermolecular interactions are shown
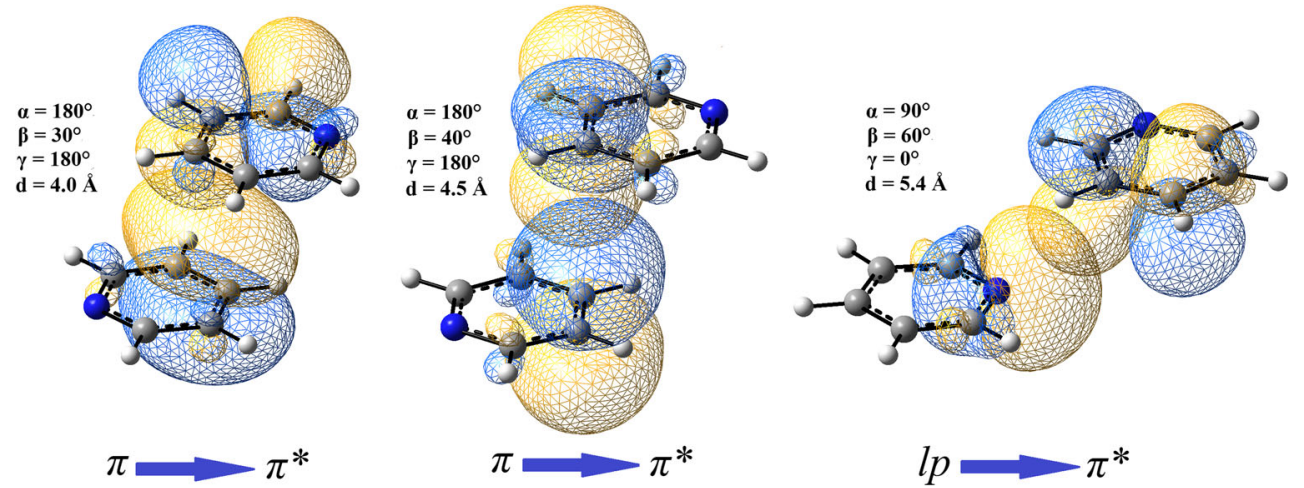

closer to the centroid of the second one. The most significant interactions are those involving antibonding $\pi$ orbitals and nitrogen's lone electron pairs (Table 6). Even considering orbital interactions of relatively small energies (down to $0.05 \mathrm{kcal} \mathrm{mol}^{-1}$ ), the interactions that could be assigned as $\mathrm{C}-\mathrm{H} \cdots \pi$ appeared to be considered as insignificant (Table 2 in the Supporting information).

ing energy. Hence, the twist angle may differ. This is also true for other system configurations. Especially for those associated with $\beta=60^{\circ}$ (Fig. 4), which may be considered as systems with $\mathrm{C}-\mathrm{H} \cdots \pi$ interactions. In their case, the twist angle of one monomer around the other does not change the energy significantly unless both monomers are in a configuration where both nitrogen atoms are relatively close to each other which leads to strong electrostatic repulsion ( $\mathrm{E}^{\text {ele }}$ term is positive in the $\alpha$ range of $\left.150-180^{\circ}\right)$ - which cannot be overcome by binding forces (Tables 6 and 7). The same is observed for higher $\beta$ angles (up to $90^{\circ}$ ) and geometries for which two nitrogen atoms face each other, except for the configurations for which $\mathrm{C}-\mathrm{H} \cdots \mathrm{N}$ hydrogen bonds can be created (the observed energy minima for $\beta=90^{\circ}$ ). It needs to be pointed out that for some $\gamma$ some configurations are symmetrically equivalent. For $\gamma=0^{\circ}$ the direction of the first monomer lateral movement (associated with the increase in $d$ and $\beta$, Fig. 2) was in accordance with the direction of the vector created between the second monomer centroid and the nitrogen atom of this monomer (the vector beginning was the position of the second monomer centroid). Hence, some pyridine dimers are symmetrically equivalent. A similar situation is found for systems with $\gamma=180^{\circ}$ for which the direction of the one monomer lateral movement was opposite to the direction of the vector created between the second monomer centroid and the nitrogen atom of this monomer-the vector beginning was the position of the second monomer centroid.

Some pyridine dimer systems (for example those with $\beta=60^{\circ}$ ) may be considered as systems with $\mathrm{C}-\mathrm{H} \cdots \pi$ interactions (Fig. 10). However, NBO analysis does not validate this claim. This also appeared to be true for dimers with lower $\beta$ where a $\mathrm{C}-\mathrm{H}$ bond of one monomer is

\section{Conclusions}

The appliance of multidimensional analysis can provide much deeper insight into the "landscape" of the interaction energies of the particular systems and enables one to see "a wider picture" of what really occurs. The combination of many different methods has revealed the complexity of the stacking interactions. Apart from providing a "literal new look" into pyridine stacking patterns another picture has emerged. A stacking interaction in pyridine dimer systems "is seen" as a combination of many different sources of energy, including orbital ones, which is true for many different geometries.

The binding geometrical boundaries of the stacked pyridine systems are relatively broad (Figs. 3 and 4 ) and this provides a great degree of flexibility in the system configuration. It is possible to result in a system configuration possessing similar energy but with different geometrical parameters. Hence, when a system is constrained to some geometrical parameters (e.g., the distance between the ring centroid and the lateral shifting of one ring along the plane of the other) it is possible to maintain the system interaction energy changing other parameters. It may give one great adjustability in the crystal engineering processes.

The "picture" of the interplay of electrostatic forces and electron correlation is clearly seen. The electron correlation effects are important for the majority of pyridine dimer geometries, even for those where the formation of $\mathrm{C}-\mathrm{H} \cdots \pi$ interactions might be proposed. The electrostatic energy is far more significant in planar dimer configurations $\left(\beta \approx 90^{\circ}\right)$ for which the formation of $\mathrm{C}-\mathrm{H} \cdots \mathrm{N}$ hydrogen bonds is plausible. 
The important role of $\pi$ orbitals in pyridine stacking has been confirmed. For this system, $\pi$-orbital interactions provide additional binding force to combine the two monomers when they are close enough to each other. This is true even for the geometries where the formation of $\mathrm{C}-\mathrm{H} \cdots \pi$ interactions might be proposed instead.

The calculated B3LYP-D3BJ interaction energies, corresponding to the found pyridine dimer configurations associated with the energy minima ( $\mathrm{PP} 1_{\text {opt }}$ and $\mathrm{PP} 2_{\text {opt }}$, Table 2$)$, are very close to those reported earlier, both for stacked and hydrogen bonded pyridine systems, being respectively equal to -3.90 and $-4.15 \mathrm{kcal} \mathrm{mol}^{-1}$ [52].

It is expected that the presented results will shed more light on stacking interaction phenomenon leading to a deeper understating of its role in natural (e.g., biological) and engineered systems. They may be of key importance in crystal structure prediction, the habit of a crystal itself, and hence, they may even find a use in modeling of a crystal possessing desired properties. The obtained PES maps (together with the performed analyses) may serve as a guide for qualitative predictions of the existence of binding interactions; even for relatively long distances between the monomer centroids (up to $7 \AA$ ). The presented study may also inspire other researchers to engage in an even deeper study of NCI phenomenon helping to understand its physics and role in a solid state as well as leading us closer to understanding the hierarchy of intermolecular interactions in a molecular crystal and biological systems.

Acknowledgments Young Scientists' Fund at the Faculty of Chemistry, Lodz University of Technology, Grant W-3D/FMN/3G/2016.

The calculations mentioned in this paper were performed using the PLATON project's infrastructure at the Lodz University of Technology Computer Center.

Open Access This article is distributed under the terms of the Creative Commons Attribution 4.0 International License (http:// creativecommons.org/licenses/by/4.0/), which permits unrestricted use, distribution, and reproduction in any medium, provided you give appropriate credit to the original author(s) and the source, provide a link to the Creative Commons license, and indicate if changes were made.

\section{References}

1. Tsuzuki S, Uchimaru T, Mikami MJ (2006) Intermolecular interaction between hexafluorobenzene and benzene: ab initio calculations including $\operatorname{CCSD}(\mathrm{T})$ level electron correlation correction. Phys Chem A 110:2027-2033

2. Tsuzuki S (2005) Interactions with aromatic rings. Struct Bond 115: 149-193

3. Mottishaw JD, Sun HJ (2013) Effects of aromatic trifluoromethylation, fluorination, and methylation on intermolecular $\pi-\pi$ interactions. Phys Chem A 117:7970-7979

4. Wan CQ, Chen XD, Mak TCW (2008) Supramolecular frameworks assembled via intermolecular lone pair-aromatic interaction between carbonyl and pyridyl groups. CrystEngComm $10: 475-478$

5. Wheeler SE, Bloom JWG (2014) Toward a more complete understanding of noncovalent interactions involving aromatic rings. Phys Chem A 118:6133-6147

6. Kruszynski R, Sierański T (2011) The intermolecular interactions in the aminonitromethylbenzenes. Cent Eur J Chem 9:94-105

7. Gholipour A, Farhadi S, Neyband RS (2016) Theoretical investigation of the nature and strength of simultaneous interactions of $\pi-\pi$ stacking and halogen bond including NMR, SAPT, AIM and NBO analysis. Struct Chem 27:1543-1551

8. Czyżnikowska Ż (2009) How does modification of adenine by hydrox$\mathrm{yl}$ radical influence the stability and the nature of stacking interactions in adenine-cytosine complex? J Mol Model 15:615-622

9. Sierański T (2016) The intricacies of the stacking interaction in a pyrrole-pyrrole system. Struct Chem 27:1107-1120

10. Kruszynski R, Sierański T (2016) Can stacking interactions exist beyond the commonly accepted limits? Cryst Growth Des 16:587595

11. Guin M, Patwari GN, Karthikeyan S (2011) Do N-heterocyclic aromatic rings prefer $\pi$-stacking? Phys Chem Chem Phys 13: $5514-5525$

12. Wu J (2014) Investigations into the nature of halogen- and hydrogen-bonding interactions of some heteroaromatic rings with dichlorine monoxide. J Mol Model 20:2424-2428

13. Buchmueller KL, Staples AM, Uthe PB, Howard CM, Pacheco KAO, Cox KK, Henry JA, Bailey SL, Horick SM, Nguyen B, Wilson WD, Lee M (2005) Molecular recognition of DNA base pairs by the formamido/pyrrole and formamido/imidazole pairings in stacked polyamides. Nucleic Acids Res 33:912-921

14. Martins P, Jesus J, Santos S, Raposo LR, Roma-Rodrigues C, Viana Baptista P, Fernandes AR (2015) Heterocyclic anticancer compounds: recent advances and the paradigm shift towards the use of Nanomedicine's tool box. Molecules 20:16852-16891

15. Dua R, Shrivastava S, Sonwane SK, Srivastava SK (2011) Pharmacological significance of synthetic heterocycles scaffold: a review. Adv Biol Res 5:120-144

16. Sinnokrot MO, Sherrill CD (2004) Highly accurate coupled cluster potential energy curves for the benzene dimer: sandwich, T-shaped, and parallel-displaced configurations. J Phys Chem A 108:1020010207

17. Hobza P, Selzle HL, Schlag EW (1994) Potential energy surface of the benzene dimer: ab initio theoretical study. J Am Chem Soc 116: 3500-3506

18. Sinnokrot MO, Valeev EF, Sherrill CD (2002) Estimates of the ab initio limit for pi-pi interactions: the benzene dimer. J Am Chem Soc 124:10887-10893

19. Zhikol OA, Shishkin OV, Lyssenko KA, Leszczynski J (2005) Electron density distribution in stacked benzene dimers: a new approach towards the estimation of stacking interaction energies. J Chem Phys 122:144104-144111

20. Ninkovic DB, Andric JM, Malkov SN, Zaric SD (2014) What are the preferred horizontal displacements of aromatic-aromatic interactions in proteins? Comparison with the calculated benzenebenzene potential energy surface. Phys Chem Chem Phys 16: 11173-11177

21. Miliordos E, Apra E, Xantheas SS (2014) Benchmark theoretical study of the $\pi-\pi$ binding energy in the benzene dimer. J Phys Chem A 118:7568-7578

22. Hwang J, Li P, Carroll WR, Smith MD, Pellechia PJ, Shimizu KD (2014) Additivity of substituent effects in aromatic stacking interactions. J Am Chem Soc 136:14060-14067

23. Malenov DP, Dragelj JL, Janjic GV, Zaric SD (2016) Coordinating benzenes stack stronger than noncoordinating benzenes, even at large horizontal displacements. Cryst Growth Des. https://doi.org/ 10.1021/acs.cgd.5b01514 
24. Li P, Zhao C, Smith MD, Shimizu KD (2013) Comprehensive experimental study of $\mathrm{N}$-heterocyclic $\pi$-stacking interactions of neutral and cationic pyridines. J Organomet Chem 78:5303-5313

25. Gung BW, Wekesa F, Barnes CL (2008) Stacking interactions between nitrogen-containing six-membered heterocyclic aromatic rings and substituted benzene: studies in solution and in the solid state. J Organomet Chem 73:1803-1808

26. Ninkovic DB, Janjic GV, Zaric SD (2012) Crystallographic and ab initio study of pyridine stacking interactions. Local nature of hydrogen bond effect in stacking interactions. Cryst Growth Des 12: 1060-1063

27. Mishra BK, Sathyamurthy N (2005) Pi-pi interaction in pyridine. J Phys Chem A 109:6-8

28. Sredojevic DN, Petrovic PV, Janjic GV, Brothers EN, Hall MB, Zaric SD (2016) The stacking interactions of bipyridine complexes: the influence of the metal ion type on the strength of interactions. J Mol Model 22:30-38

29. An Y, Doney AC, Andrade RB, Wheeler SE (2016) Stacking interactions between 9-Methyladenine and heterocycles commonly found in pharmaceuticals. J Chem Inf Model 56:906-914

30. Megiel E, Kasprzycka-Guttman T, Jagielska A, Wróblewska L (2001) A theoretical and experimental 14N NMR study of association of pyridine. J Mol Struct 569:111-119

31. Bezbaruah B, Hazarika P, Gogoi A, Medhi OK, Medhi C (2011) Interaction of small aromatic molecules: an ab initio studies on benzene and pyridine molecules. J Biophys Chem 1:32-36

32. Sherrill CD (2013) Energy component analysis of $\pi$ interactions. Acc Chem Res 46:1020-1028

33. Smith QA, Gordon MS, Slipchenko LV (2011) Benzene-pyridine interactions predicted by the effective fragment potential method. Phys Chem A 115:4598-4609

34. Hohenstein EG, Sherrill CD (2009) Effects of heteroatoms on aromatic $\pi-\pi$ interactions: benzene-pyridine and pyridine dimer. $\mathrm{J}$ Phys Chem A 113:878-886

35. Zhang J, Gao Y, Yao W, Li S, Tao FM (2014) Ab initio study of the $\pi-\pi$ interaction in the pyridine dimer: effects of bond functions. Comp Theor Chem 1049:82-89

36. Sladek V, Ilcin M (2013) Ab initio study of the structure and energetic of pyridine dimers. Acta Chim Slov 6:187-193

37. Mishra BK, Arey JS, Sathyamurthy N (2010) Stacking and spreading interaction in N-heteroaromatic systems. J Phys Chem A 114: 9606-9616

38. Piacenza M, Grimme S (2005) Van der Waals interactions in aromatic systems: structure and energetics of dimers and trimers of pyridine. ChemPhysChem 6:1554-1558

39. Ninkovic DB, Vojislavljevic-Vasilev DZ, Medakovic VB, Hall MB, Brothers EN, Zaric SD (2016) Aliphatic-aromatic stacking interactions in cyclohexane-benzene are stronger than aromatic-aromatic interaction in the benzene dimer. Phys Chem Chem Phys 18: 25791-25795

40. Ninkovic DB, Andric JM, Zaric SD (2013) Parallel interactions at large horizontal displacement in pyridine-pyridine and benzenepyridine dimers. ChemPhysChem 14:237-243

41. Allen FH (2002) The Cambridge structural database: a quarter of a million crystal structures and rising. Act Cryst B 58:380-388

42. Geronimo I, Lee EC, Singh NJ, Kim KS (2010) How different are electron-rich and electron-deficient $\pi$ interactions? J Chem Theory Comput 6:1931-1934

43. Chaubey A, Pandeya SN (2011) Pyridine a versatile nucleuse in pharmaceutical field. Asian J Pharm Clin Res 4:5-8

44. Friesner RA (2005) Ab initio quantum chemistry: methodology and applications. Proc Natl Acad Sci 102:6648-6653

45. Grimme S, Antony J, Ehrlich S, Krieg H (2010) A consistent and accurate $\mathrm{ab}$ initio parametrization of density functional dispersion correction (DFT-D) for the 94 elements H-Pu. J Chem Phys 132: 154104-154122
46. Grimme S, Ehrlich S, Goerigk L (2011) Effect of the damping function in dispersion corrected density functional theory. J Comput Chem 32:1456-1465

47. Grimme S (2011) Density functional theory with London dispersion corrections. Comput Mol Sci 1:211-228

48. Zhao Y, Truhlar DG (2008) Density functionals with broad applicability in chemistry. Acc Chem Res 41:157-167

49. Zhao Y, Truhlar DG (2008) The M06 suite of density functionals for main group thermochemistry, thermochemical kinetics, noncovalent interactions, excited states, and transition elements: two new functionals and systematic testing of four M06-class functionals and 12 other functionals. Theor Chem Account 120:215241

50. Li A, Muddana HS, Gilson MK (2014) Quantum mechanical calculation of noncovalent interactions: a large-scale evaluation of PMx, DFT, and SAPT approaches. J Chem Theory Comput 10: $1563-1575$

51. Brauer B, Kesharwani MK, Kozuch S, Martin JML (2016) The S66x8 benchmark for noncovalent interactions revisited: explicitly correlated ab initio methods and density functional theory. Phys Chem Chem Phys 18:20905-20925

52. Rezac J, Riley KE, Hobza P (2011) S66: a well-balanced database of benchmark interaction energies relevant to biomolecular structures. J Chem Theory Comput 7:2427-2438

53. Rezac J, Jurecka P, Riley KE, Cerny J, Valdes H, Pluhackova K, Berka K, Rezac T, Pitonak M, Vondrasek J, Hobza P (2008) Quantum chemical benchmark energy and geometry database for molecular clusters and complex molecular systems (www.begdb. com): a users manual and examples. Collect Czechoslov Chem Commun 73:1261-1270

54. Frisch MJ, Trucks GW, Schlegel HB, Scuseria GE, Robb MA, Cheeseman JR, Scalmani G, Barone V, Mennucci B, Petersson GA, Nakatsuji H, Caricato M, Li X, Hratchian HP, Izmaylov AF, Bloino J, Zheng G, Sonnenberg JL, Hada M, Ehara M, Toyota K, Fukuda R, Hasegawa J, Ishida M, Nakajima T, Honda Y, Kitao O, Nakai H, Vreven T, Montgomery JA Jr, Peralta JE, Ogliaro F, Bearpark M, Heyd JJ, Brothers E, Kudin KN, Staroverov VN, Kobayashi R, Normand J, Raghavachari K, Rendell A, Burant JC, Iyengar SS, Tomasi J, Cossi M, Rega N, Millam JM, Klene M, Knox JE, Cross JB, Bakken V, Adamo C, Jaramillo J, Gomperts R, Stratmann RE, Yazyev O, Austin AJ, Cammi R, Pomelli C, Ochterski JW, Martin RL, Morokuma K, Zakrzewski VG, Voth GA, Salvador P, Dannenberg JJ, Dapprich S, Daniels AD, Farkas Ö, Foresman JB, Ortiz JV, Cioslowski J, Fox DJ (2009) Gaussian 09, revision D.01. Gaussian Inc., Wallingford

55. Møller C, Plesset MS (1934) Note on an approximation treatment for many-electron systems. Phys Rev 46:618-622

56. Boys DF, Bernardi F (1970) The calculation of small molecular interactions by the differences of separate total energies. Some procedures with reduced errors. Mol Phys 19:553-566

57. Origin (2003) Origin 7.5. OriginLab, Northampton, MA

58. Su P, Li H (2009) Energy decomposition analysis of covalent bonds and intermolecular interactions. J Chem Phys 131:14102-14116

59. Kitaura K, Morokuma K (1976) A new energy decomposition scheme for molecular interactions within the Hartree-Fock approximation. Int J Quantum Chem 10:325-340

60. Ziegler T, Rauk A (1979) Carbon monoxide, carbon monosulfide, molecular nitrogen, phosphorus trifluoride, and methyl isocyanide as .Sigma. Donors and .Pi. Acceptors. A theoretical study by the Hartree-Fock-slater transition-state method. Inorg Chem 18:1755-1759

61. Hayes IC, Stone AJ (1984) An intermolecular perturbation theory for the region of moderate overlap. Mol Phys 53:83-105

62. Schmidt MW, Baldridge KK, Boatz JA, Elbert ST, Gordon MS, Jensen JH, Koseki S, Matsunaga N, Nguyen KA, Su S, Windus TL, Dupuis M, Montgomery JA (1993) General atomic and molecular electronic structure system. J Comput Chem 14:1347-1363 
63. Gordon MS, Schmidt MW (2005) Advances in electronic structure theory: GAMESS a decade later. In: Dykstra CE, Frenking G, Kim KS, Scuseria GE (eds) Theory and applications of computational chemistry: the first forty years. Elsevier, Amsterdam

64. Carrazana-Garcia JA, Cabaleiro-Lago EM, Campo-Cacharron A, Rodriguez-Otero J (2014) A theoretical study of ternary indolecation-anion complexes. Org Biomol Chem 12:9145-9156

65. Campo-Cacharron A, Cabaleiro-Lago EM, Carrazana-Garcia JA, Rodriguez-Otero J (2014) Interaction of aromatic units of amino acids with guanidinium cation: the interplay of $\pi \cdots \pi, \mathrm{X}-\mathrm{H} \cdots \pi$, and M+* $\pi$ contacts. J Comput Chem 35:1290-1301

66. Priya AM, Senthilkumar L, Kolandaivel P (2014) Hydrogenbonded complexes of serotonin with methanol and ethanol: a DFT study. Struct Chem 25:139-157

67. Pereira Orenha R, Vessecchi R, Galembeck SE (2015) The resonance of cation and anion radicals with multiple conjugated bonds. Struct Chem 26:365-373
68. Jimenez-Moreno E, Jimenez-Oses G, Gomez AM, Santana AG, Corzana F, Bastida A, Jimenez-Barbero J, Asensio JL (2015) A thorough experimental study of $\mathrm{CH} / \pi$ interactions in water: quantitative structure-stability relationships for carbohydrate/aromatic complexes. Chem Sci 6:6076-6085

69. Hu H, Lu Z, Yang W (2007) Fitting molecular electrostatic potentials from quantum mechanical calculations. J Chem Theory Comput 3:1004-1013

70. Breneman CM, Wiberg KB (1990) Determining atom-centered monopoles from molecular electrostatic potentials. The need for high sampling density in formamide conformational analysis. J Comput Chem 11:361-373

71. Grimme $S$ (2008) Do special noncovalent $\pi-\pi$ stacking interactions really exist? Angew Chem Int Ed 47:3430-3434

72. Lutz PB, Bayse CA (2013) Orbital-based insights into paralleldisplaced and twisted conformations in $\pi-\pi$ interactions. Phys Chem Chem Phys 15:9397-9406 